\title{
OPTIMAL FISCAL AND \\ MONETARY POLICY \\ IN A MEDIUM-SCALE \\ MACROECONOMIC MODEL
}

by Stephanie Schmitt-Grohé and Martin Uribe 
EUROPEAN CENTRAL BANK

\title{
WORKING PAPER SERIES
}

NO 6 I 2 / APRIL 2006

\author{
INTERNATIONAL RESEARCH \\ FORUM ON MONETARY POLICY \\ OPTIMAL FISCAL AND \\ MONETARY POLICY \\ IN A MEDIUM-SCALE \\ MACROECONOMIC MODEL'
}

by Stephanie Schmitt-Grohé ${ }^{2}$

and Martín Uribe ${ }^{3}$

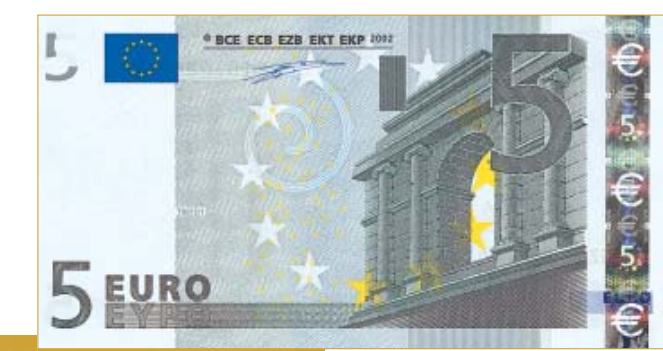

In 2006 all ECB

publications

will feature

a motif taken

from the

$€ 5$ banknote.

This paper can be downloaded without charge from http://www.ecb.int or from the Social Science Research Network electronic library at http://ssrn.com/abstract_id=8910II

I The views expressed in this paper are those of the authors and do not do not necessarily represent those of the European Central Bank. We would like to thank Jesús Fernández-Villaverde, Mark Gertler, Marc Giannoni, Andy Levin, Kenneth Rogoff, Mike Woodford, and seminar participants at the April 2005 NBER Macroeconomics Annual meeting and the May 2005 ECB International Research Forum for comments.

2 Duke University, CEPR, and NBER. Mailling address: Duke University, Durham, NC 27708, United States; Phone: 919 660-1889. E-mail: grohe@duke.edu 3 Duke University and NBER. Mailling address: Duke University, Durham, NC 27708, United States; Phone: 919 660-1888. E-mail: uribe@duke.edu 


\section{International Research Forum on Monetary Policy: Third Conference}

This paper was presented at the third conference of the International Research Forum on Monetary Policy which took place on May 20-21, 2005 at the ECB. The Forum is sponsored by the European Central Bank, the Board of Governors of the Federal Reserve System, the Center for German and European Studies at Georgetown University and the Center for Financial Studies at Goethe University. Its purpose is to encourage research on monetary policy issues that are relevant from a global perspective. It regularly organises conferences held alternately in the Euro Area and the United States. The conference organisers were Ignazio Angeloni, Matt Canzoneri, Dale Henderson, and Volker Wieland. The conference programme, including papers and discussions, can be found on the ECB's web site (http://www.ecb.int/events/conferences/html/intforum3.en.html)

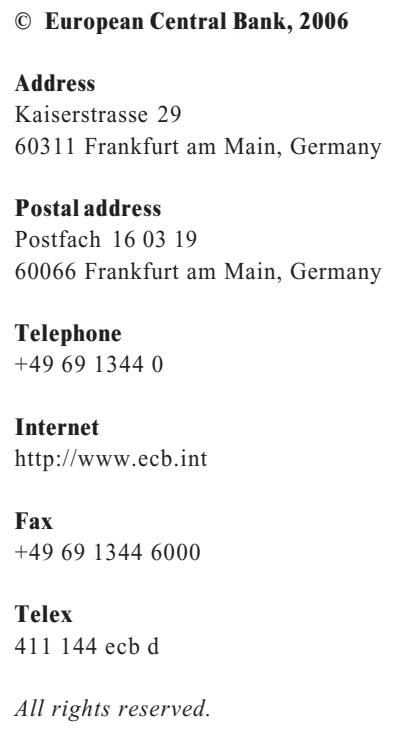

The views expressed in this paper do not necessarily reflect those of the European Central Bank. 


\section{CONTENTS}

Abstract 4

Non-technical summary 5

1. Introduction 7

2. The model \|\|

2.1 The private sector \|ा

2.2 The government 18

2.3 Calibration $\| 9$

3. The Ramsey steady state 20

3.1 The optimal level of inflation 20

3.2 Optimal tax rates 23

4. Ramsey dynamics under income taxation 25

4.1 Nominal rigidities and optimal policy 27

4.2 Indexation and optimal policy 30

5. Optimized policy rules 32

5.1 Welfare under the optimized rule 35

5.2 Ramsey and optimized impulse responses 36

5.3 Ramsey policy with a single instrument 37

6. Capital and labor taxation 38

6.1 Time to tax 40

6.2 Capital tax volatility and cost of varying capacity utilization $4 \|$

7. Conclusion 4 II

References 44

Footnotes $\quad 47$

Tables and figures $\quad 50$

European Central Bank Working Paper Series $\quad 60$ 


\begin{abstract}
In this paper, we study Ramsey-optimal fiscal and monetary policy in a mediumscale model of the U.S. business cycle. The model features a rich array of real and nominal rigidities that have been identified in the recent empirical literature as salient in explaining observed aggregate fluctuations. The main result of the paper is that price stability appears to be a central goal of optimal monetary policy. The optimal rate of inflation under an income tax regime is half a percent per year with a volatility of 1.1 percent. This result is surprising given that the model features a number of frictions that in isolation would call for a volatile rate of inflation-particularly nonstate-contingent nominal public debt, no lump-sum taxes, and sticky wages. Under an income-tax regime, the optimal income tax rate is quite stable, with a mean of 30 percent and a standard deviation of 1.1 percent. JEL Classification: E52, E61, E63. Keywords: Ramsey Policy, Inflation Stabilization, Tax Smoothing, Time to Tax, Nominal and Real Rigidities.
\end{abstract}




\section{Non-Technical Summary}

This paper addresses a classic question in macroeconomics, namely, how should a benevolent government conduct stabilization policy. A central characteristic of all existing studies is that optimal policy is derived in highly stylized environments. Typically, optimal policy is characterized for economies with a single or a very small number of deviations from the frictionless neoclassical paradigm. A case in point are the numerous recent studies concerned with optimal monetary policy within the context of the two-equation, one-friction, neoKeynesian model without capital accumulation. An advantage of this stylized approach to optimal stabilization policy is that it facilitates understanding the ways in which policy should respond to mitigate the distortionary effects of a particular friction in isolation.

An important drawback of studying optimal stabilization policy one distortion at a time is that highly simplified models are unlikely to provide a satisfactory account of cyclical movements for more than just a few macroeconomic variables of interest. For this reason, the usefulness of this strategy to produce policy advice for the real world is necessarily limited.

The approach to optimal policy that we propose in this paper departs from the literature extant in that it is based on a rich medium-scale theoretical framework capable of explaining observed business cycle fluctuations for a wide range of nominal and real variables. Following the lead of Kimball (1995), the model emphasizes the importance of combining nominal as well as real rigidities in explaining the propagation of macroeconomic shocks. Specifically, the model features four nominal frictions, sticky prices, sticky wages, a demand for money by households, and a cash-in-advance constraint on the wage bill of firms, and five sources of real rigidities, investment adjustment costs, variable capacity utilization, habit formation, imperfect competition in product and factor markets, and distortionary taxation. Aggregate fluctuations are assumed to be driven by supply shocks, which take the form of stochastic variations in total factor productivity, and demand shocks stemming from exogenous innovations to the level of government purchases and the level of government transfers. Altig et al. (2004) and Christiano, Eichenbaum, and Evans (2005) argue that the model economy for which we seek to design optimal policy can indeed explain the observed responses of inflation, real wages, nominal interest rates, money growth, output, investment, consumption, labor productivity, and real profits to productivity and monetary shocks in the postwar United States. In this respect, the present paper aspires to be a step ahead in the research program of generating policy evaluation that is of relevance for actual policy making.

The government is assumed to be benevolent in the Ramsey sense, that is, it seeks to bring about the competitive equilibrium that maximizes the lifetime utility of the representative agent and has access to a commitment technology that allows it to honor its promises. The policy instruments available to the government are assumed to be taxes on income, possibly, differentiated across different sources of income, and the short-term nominal interest rate. Public debt is assumed to be nominal and non-state contingent.

A key finding of the paper is that price stability appears to be a central goal of optimal monetary policy. The optimal rate of inflation under an income tax regime is 0.5 percent per year with a volatility of 1.1 percent. In this sense, price stickiness emerges as the single most important distortion shaping optimal policy. This result is surprising given that the model features a number of other frictions that in isolation would call for a volatile rate of inflation 
with a mean different from zero. First, the fact that nominal government debt is non-state contingent and that regular taxes are distortionary, makes it attractive for the Ramsey planner to use unexpected variations in inflation as a lump-sum tax on private holdings of nominal government liabilities. This is indeed the reason why in flexible price environments the optimal inflation volatility is very high (see, for example, Calvo and Guidotti, 1990, 1993; and Chari et al. 1991). Second, the fact that nominal wages are sticky provides an incentive for the government to set the price level so as to engineer the efficient real wage. This practice, when studied in isolation, also makes high inflation volatility optimal.

When the fiscal authority is allowed to tax capital and labor income at different rates, optimal fiscal policy is characterized by a large and volatile subsidy on capital. It is well known from the work of Judd (2002) that in the presence of imperfect competition in product markets optimal taxation calls for a subsidy on capital of a magnitude approximately equal to the markup of prices over marginal cost. However, our results suggest that the optimal capital subsidy is much larger than the one identified in the work of Judd. The reason for this discrepancy is that capital depreciation in combination with a depreciation allowance, which is ignored in the work of Judd, exacerbates the need to subsidize capital. This is because the markup distorts the gross rate of return on capital whereas the subsidy applies to the return on capital net of depreciation.

Ramsey outcomes are mute on the issue of what policy regimes can implement them. The information on policy one can extract from the solution to the Ramsey problem is limited to the equilibrium behavior of policy variables such as tax rates, the nominal interest rate, etc. as a function of the state of the economy. Even if the policymaker could observe the state of the economy, using the equilibrium process of the policy variables to define a policy regime would not guarantee the Ramsey outcome as the competitive equilibrium. The problem is that such a policy regime could give rise to multiple equilibria. We address the issue of implementation of optimal policy by limiting attention to simple monetary and fiscal rules. These rules are defined over a small set of readily available macro indicators and are designed to ensure local uniqueness of the rational expectations equilibrium. We find parameterizations of such policy rules capable of inducing equilibrium dynamics fairly close to those associated with the Ramsey equilibrium. 


\section{Introduction}

This paper addresses a classic question in macroeconomics, namely, how should a benevolent government conduct stabilization policy. A central characteristic of all existing studies is that optimal policy is derived in highly stylized environments. Typically, optimal policy is characterized for economies with a single or a very small number of deviations from the frictionless neoclassical paradigm. A case in point are the numerous recent studies concerned with optimal monetary policy within the context of the two-equation, one-friction, neoKeynesian model without capital accumulation. ${ }^{1}$ Another example of studies in which the optimal policy design problem is analyzed within theoretical frameworks featuring a small number of rigidities include models with flexible prices and distorting income taxes (Lucas and Stokey, 1983; Schmitt-Grohé and Uribe, 2004b). An advantage of this stylized approach to optimal stabilization policy is that it facilitates understanding the ways in which policy should respond to mitigate the distortionary effects of a particular friction in isolation.

An important drawback of studying optimal stabilization policy one distortion at a time is that highly simplified models are unlikely to provide a satisfactory account of cyclical movements for more than just a few macroeconomic variables of interest. For this reason, the usefulness of this strategy to produce policy advice for the real world is necessarily limited.

The approach to optimal policy that we propose in this paper departs from the literature extant in that it is based on a rich medium-scale theoretical framework capable of explaining observed business cycle fluctuations for a wide range of nominal and real variables. Following the lead of Kimball (1995), the model emphasizes the importance of combining nominal as well as real rigidities in explaining the propagation of macroeconomic shocks. Specifically, the model features four nominal frictions, sticky prices, sticky wages, a demand for money by households, and a cash-in-advance constraint on the wage bill of firms, and five sources of real rigidities, investment adjustment costs, variable capacity utilization, habit formation, imperfect competition in product and factor markets, and distortionary taxation. Aggregate 
fluctuations are assumed to be driven by supply shocks, which take the form of stochastic variations in total factor productivity, and demand shocks stemming from exogenous innovations to the level of government purchases and the level of government transfers. Altig et al. (2004) and Christiano, Eichenbaum, and Evans (2005) argue that the model economy for which we seek to design optimal policy can indeed explain the observed responses of inflation, real wages, nominal interest rates, money growth, output, investment, consumption, labor productivity, and real profits to productivity and monetary shocks in the postwar United States. In this respect, the present paper aspires to be a step ahead in the research program of generating policy evaluation that is of relevance for actual policy making.

The government is assumed to be benevolent in the Ramsey sense, that is, it seeks to bring about the competitive equilibrium that maximizes the lifetime utility of the representative agent and has access to a commitment technology that allows it to honor its promises. The policy instruments available to the government are assumed to be taxes on income, possibly, differentiated across different sources of income, and the short-term nominal interest rate. Public debt is assumed to be nominal and non-state contingent.

A key finding of the paper is that price stability appears to be a central goal of optimal monetary policy. The optimal rate of inflation under an income tax regime is 0.5 percent per year with a volatility of 1.1 percent. In this sense, price stickiness emerges as the single most important distortion shaping optimal policy. This result is surprising given that the model features a number of other frictions that in isolation would call for a volatile rate of inflation with a mean different from zero.

Consider first the forces calling for an optimal inflation rate that is different from zero. As is well known, the presence of a demand for money by households provides an incentive to drive inflation down to a level consistent with the Friedman rule. In this paper, we identify two additional reasons why the Ramsey planner may want to deviate from price stability. First, under an income tax regime, i.e., when all sources of income are taxed at the same rate, the Ramsey planner has an inflationary bias originating from the fact that it is less 
distorting to tax labor income than it is to tax capital income. With a cash-in-advance constraint on the wage bill of firms, inflation acts as a tax on labor income. Second, the Ramsey planner has an incentive to tax away transfers as they represent pure rents accruing to households. Without a direct instruments to tax transfers, the government imposes an indirect levy on this source of household income via the inflation tax.

Optimal policy calls for low inflation volatility in spite of the following two distortions that by themselves call for high inflation volatility. First, the fact that nominal government debt is non-state contingent and that regular taxes are distortionary, makes it attractive for the Ramsey planner to use unexpected variations in inflation as a lump-sum tax on private holdings of nominal government liabilities. This is indeed the reason why in flexible price environments the optimal inflation volatility is very high (see, for example, Calvo and Guidotti, 1990, 1993; and Chari et al. 1991). Second, the fact that nominal wages are sticky provides an incentive for the government to set the price level so as to engineer the efficient real wage. This practice, when studied in isolation, also makes high inflation volatility optimal.

When the fiscal authority is allowed to tax capital and labor income at different rates, optimal fiscal policy is characterized by a large and volatile subsidy on capital. It is well known from the work of Judd (2002) that in the presence of imperfect competition in product markets optimal taxation calls for a subsidy on capital of a magnitude approximately equal to the markup of prices over marginal cost. However, our results suggest that the optimal capital subsidy is much larger than the one identified in the work of Judd. The reason for this discrepancy is that capital depreciation in combination with a depreciation allowance, which is ignored in the work of Judd, exacerbates the need to subsidize capital. This is because the markup distorts the gross rate of return on capital whereas the subsidy applies to the return on capital net of depreciation.

In our model, the optimal capital subsidy is extremely volatile. Its standard deviation is 150 percent. The high volatility of capital income taxes emerges for the familiar reason that 
capital is a fixed factor of production in the short run, so the fiscal authority uses unexpected changes in the capital income tax rate as a shock absorber for innovations in its budget (see, for example, Judd, 1992). We identify two frictions capable of driving this high volatility down significantly. One is time to tax. When tax rates are determined four quarters in advance, the optimal volatility of the capital income tax rate falls to about 50 percent. This is because the tax elasticity of the demand for capital increases with the number of periods between the announcement of the tax rate and its application. The second friction that is important in understanding the volatility of capital taxes is investment adjustment cost. Intuitively, the higher are the impediments to adjust the level of investment, the lower is the elasticity of capital with respect to temporary changes in tax rates. In the absence of investment adjustment costs, the optimal volatility of the capital income tax rate falls to 65 percent. Furthermore, in an environment with 4 periods of time to tax and no capital adjustment cost, the optimal capital income tax has a volatility of 25 percent.

Ramsey outcomes are mute on the issue of what policy regimes can implement them. The information on policy one can extract from the solution to the Ramsey problem is limited to the equilibrium behavior of policy variables such as tax rates, the nominal interest rate, etc. as a function of the state of the economy. Even if the policymaker could observe the state of the economy, using the equilibrium process of the policy variables to define a policy regime would not guarantee the Ramsey outcome as the competitive equilibrium. The problem is that such a policy regime could give rise to multiple equilibria. We address the issue of implementation of optimal policy by limiting attention to simple monetary and fiscal rules. These rules are defined over a small set of readily available macro indicators and are designed to ensure local uniqueness of the rational expectations equilibrium. We find parameterizations of such policy rules capable of inducing equilibrium dynamics fairly close to those associated with the Ramsey equilibrium.

Finally, a methodological contribution of this paper is the development of a set of numerical tools that allow the computation of Ramsey policy in a general class of stochastic 
dynamic general equilibrium models. Matlab code to implement these computations is publicly available at the authors' websites.

The remainder of the paper is organized in six sections. Section 2 presents the theoretical model and its calibration. Section 3 characterizes the Ramsey steady state. Section 4 studies the Ramsey dynamics in an economy where the fiscal authority is constrained to taxing all sources of income at the same rate. Section 5 identifies simple interest-rate and tax rules capable of mimicking well the Ramsey equilibrium dynamics. Section 6 studies the Ramsey problem in an economy in which capital and labor can be taxed at different rates. This section also analyzes the consequences of time to tax. Section 7 concludes.

\section{The Model}

The essential elements of the model economy that serves as the basis for our study of stabilization policy are taken from a recent paper by Christiano, Eichenbaum, and Evans (2005). This model and variations thereof have been estimated by a number of authors in past couple of years. The structure of the model is the standard neoclassical growth model augmented with a number of real and nominal frictions. The nominal frictions are sticky prices, sticky wages, a money demand by households, and a money demand by firms. The real frictions consist of monopolistic competition in product and factor markets, habit formation, investment adjustment costs, variable capacity utilization, and distortionary taxation.

We keep the description of the model brief and refer the reader to the expanded version of this paper (Schmitt-Grohé and Uribe, 2005b) for a more detailed exposition.

\subsection{The Private Sector}

The economy is assumed to be populated by a large representative family with a continuum of members. Consumption and hours worked are identical across family members. The household's preferences are defined over per capita consumption, $c_{t}$, and per capita labor 
effort, $h_{t}$, and are described by the utility function

$$
E_{0} \sum_{t=0}^{\infty} \beta^{t} \frac{\left[\left(c_{t}-b c_{t-1}\right)^{1-\phi_{4}}\left(1-h_{t}\right)^{\phi_{4}}\right]^{1-\phi_{3}}-1}{1-\phi_{3}}
$$

where $E_{t}$ denotes the mathematical expectations operator conditional on information available at time $t, \beta \in(0,1)$ represents a subjective discount factor, and $\phi_{3}>0$ and $\phi_{4} \in(0,1)$ are parameters. Preferences display internal habit formation, measured by the parameter $b \in[0,1)$. The consumption good is assumed to be a composite made of a continuum of differentiated goods $c_{i t}$ indexed by $i \in[0,1]$ via the aggregator

$$
c_{t}=\left[\int_{0}^{1} c_{i t}^{1-1 / \eta} d i\right]^{1 /(1-1 / \eta)},
$$

where the parameter $\eta>1$ denotes the intratemporal elasticity of substitution across different varieties of consumption goods.

For any given level of consumption of the composite good, purchases of each individual variety of goods $i \in[0,1]$ in period $t$ must solve the dual problem of minimizing total expenditure, $\int_{0}^{1} P_{i t} c_{i t} d i$, subject to the aggregation constraint (1), where $P_{i t}$ denotes the nominal price of a good of variety $i$ at time $t$. The demand for goods of variety $i$ is then given by

$$
c_{i t}=\left(\frac{P_{i t}}{P_{t}}\right)^{-\eta} c_{t}
$$

where $P_{t}$ is a nominal price index defined as

$$
P_{t} \equiv\left[\int_{0}^{1} P_{i t}^{1-\eta} d i\right]^{\frac{1}{1-\eta}}
$$

This price index has the property that the minimum cost of a bundle of intermediate goods yielding $c_{t}$ units of the composite good is given by $P_{t} c_{t}$.

Labor decisions are made by a central authority within the household, a union, which 
supplies labor monopolistically to a continuum of labor markets of measure 1 indexed by $j \in[0,1]$. In each labor market $j$, the union faces a demand for labor given by $\left(W_{t}^{j} / W_{t}\right)^{-\tilde{\eta}} h_{t}^{d}$. Here $W_{t}^{j}$ denotes the nominal wage charged by the union in labor market $j$ at time $t, W_{t}$ is an index of nominal wages prevailing in the economy, and $h_{t}^{d}$ is a measure of aggregate labor demand by firms. In each particular labor market, the union takes $W_{t}$ and $h_{t}^{d}$ as exogenous. The case in which the union takes aggregate labor variables as endogenous can be interpreted as an environment with highly centralized labor unions. Higher-level labor organizations play an important role in some European and Latin American countries, but are less prominent in the United States. Given the wage charged in each labor market $j \in[0,1]$, the union is assumed to supply enough labor, $h_{t}^{j}$, to satisfy demand. That is,

$$
h_{t}^{j}=\left(\frac{w_{t}^{j}}{w_{t}}\right)^{-\tilde{\eta}} h_{t}^{d},
$$

where $w_{t}^{j} \equiv W_{t}^{j} / P_{t}$ and $w_{t} \equiv W_{t} / P_{t}$. In addition, the total number of hours allocated to the different labor markets must satisfy the resource constraint $h_{t}=\int_{0}^{1} h_{t}^{j} d j$. Combining this restriction with equation (2), we obtain

$$
h_{t}=h_{t}^{d} \int_{0}^{1}\left(\frac{w_{t}^{j}}{w_{t}}\right)^{-\tilde{\eta}} d j .
$$

Our setup of imperfectly competitive labor markets departs from most existing expositions of models with nominal wage inertia. For in these models, it is assumed that each household supplies a differentiated type of labor input. This assumption introduces equilibrium heterogeneity across households in the number of hours worked. To avoid this heterogeneity from spilling over into consumption heterogeneity, it is typically assumed that preferences are separable in consumption and hours and that financial markets exist that allow agents to fully insure against employment risk. Our formulation has the advantage that it avoids the need to assume both separability of preferences in leisure and consumption and the existence 
of such insurance markets. As we will explain later in more detail, our specification gives rise to a wage-inflation Phillips curve with a larger coefficient on the wage-markup gap that the model with employment heterogeneity across households.

The household is assumed to own physical capital, $k_{t}$, which accumulates according to the following law of motion

$$
k_{t+1}=(1-\delta) k_{t}+i_{t}\left[1-\frac{\kappa}{2}\left(\frac{i_{t}}{i_{t-1}}-1\right)^{2}\right] \text {, }
$$

where $i_{t}$ denotes gross investment and $\delta$ is a parameter denoting the rate of depreciation of physical capital. The process of capital accumulation is subject to investment adjustment costs. These assumed functional form for the adjustment-cost function implies that up to first order adjustment costs are nil in the vicinity of the deterministic steady state. The parameter $\kappa$ is positive.

Owners of physical capital can control the intensity at which this factor is utilized. Formally, we let $u_{t}$ measure capacity utilization in period $t$. We assume that using the stock of capital with intensity $u_{t}$ entails a cost of $\left[\gamma_{1}\left(u_{t}-1\right)+\gamma_{2} / 2\left(u_{t}-1\right)^{2}\right] k_{t}$ units of the composite final good. The parameters $\gamma_{1}$ and $\gamma_{2}$ take on positive values. Both the specification of capital adjustment costs and capacity utilization costs are somewhat peculiar. More standard formulations assume that adjustment costs depend on the level of investment rather than on its growth rate, as is assumed here. Also, costs of capacity utilization typically take the form of a higher rate of depreciation of physical capital. The modeling choice here is guided by the need to fit the response of investment and capacity utilization to a monetary shock in the US economy. For further discussion of this point, see Christiano, Eichenbaum, and Evans (2005, section 6.1) and Altig et al. (2004).

Households rent the capital stock to firms at the real rental rate $r_{t}^{k}$ per unit of capital. Thus, total income stemming from the rental of capital is given by $r_{t}^{k} u_{t} k_{t}$. The investment good is assumed to be a composite good made with the aggregator function (1). Thus, 
the demand for each intermediate good $i \in[0,1]$ for investment purposes, $i_{i t}$, is given by $i_{i t}=i_{t}\left(P_{i t} / P_{t}\right)^{-\eta}$

As in earlier related work (Schmitt-Grohé and Uribe, 2004a) and Altig et al. (2004), we motivate a demand for money by households by assuming that purchases of consumption are subject to a proportional transaction cost that is increasing in consumption based money velocity. Formally, the purchase of each unit of consumption entails a cost given by $\phi_{1} v_{t}+$ $\phi_{2} / v_{t}-2 \sqrt{\phi_{1} \phi_{2}}$. Here,

$$
v_{t} \equiv \frac{c_{t}}{m_{t}^{h}}
$$

is the ratio of consumption to real money balances held by the household, which we denote by $m_{t}^{h}$. The functional form assumed for the transaction cost technology ensures that the Friedman rule, i.e., a zero nominal interest rate, need not be associated with an infinite demand for money. It also implies that both the transaction cost and the distortion it introduces vanish when the nominal interest rate is zero. The transaction cost function also guarantees that in equilibrium money velocity is always greater than or equal to a satiation level given by $\sqrt{\phi_{2} / \phi_{1}}$. Our specification of the transaction technology ensures that the demand for money is decreasing in the nominal interest rate.

Households are assumed to have access to a complete set of nominal state-contingent assets. Specifically, each period $t \geq 0$, consumers can purchase any desired state-contingent nominal payment $X_{t+1}^{h}$ in period $t+1$ at the dollar cost $E_{t} r_{t, t+1} X_{t+1}^{h}$. The variable $r_{t, t+1}$ denotes a stochastic nominal discount factor between periods $t$ and $t+1$. Households must pay taxes on labor income, capital income, and profits. We denote by $\tau_{t}^{h}, \tau_{t}^{k}$, and $\tau_{t}^{\phi}$, respectively, the labor income tax rate, the capital income tax rate, and the profit tax rate in period $t$. A tax allowance is assumed to apply to costs due to depreciation. Households receive real lump-sum transfers from the government in the amount $n_{t}$ per period. The 
household's period-by-period budget constraint is given by:

$$
\begin{gathered}
E_{t} r_{t, t+1} x_{t+1}^{h}+c_{t}\left[1+\phi_{1} v_{t}+\phi_{2} / v_{t}-2 \sqrt{\phi_{1} \phi_{2}}\right]+i_{t}+m_{t}^{h}=\frac{x_{t}^{h}+m_{t-1}^{h}}{\pi_{t}}+n_{t} \\
+\left(1-\tau_{t}^{k}\right)\left[r_{t}^{k} u_{t}-\gamma_{1}\left(u_{t}-1\right)-\gamma_{2} / 2\left(u_{t}-1\right)^{2}\right] k_{t}+ \\
\tau_{t}^{k} q_{t} \delta k_{t}+\left(1-\tau_{t}^{h}\right) h_{t}^{d} \int_{0}^{1} w_{t}^{j}\left(\frac{w_{t}^{j}}{w_{t}}\right)^{-\tilde{\eta}} d j+\left(1-\tau_{t}^{\phi}\right) \phi_{t} .
\end{gathered}
$$

The variable $x_{t}^{h} / \pi_{t} \equiv X_{t}^{h} / P_{t}$ denotes the real payoff in period $t$ of nominal state-contingent assets purchased in period $t-1$. The variable $\phi_{t}$ denotes dividends received from the ownership of firms, $q_{t}$ denotes the price of capital in terms of consumption, and $\pi_{t} \equiv P_{t} / P_{t-1}$ denotes the gross rate of consumer-price inflation.

We introduce wage stickiness in the model by assuming that each period the household (or union) cannot set the nominal wage optimally in a fraction $\tilde{\alpha} \in[0,1)$ of randomly chosen labor markets. In these markets, the wage rate is indexed to the previous period's consumerprice inflation according to the rule $W_{t}^{j}=W_{t-1}^{j} \pi_{t-1}^{\tilde{\chi}}$, where $\tilde{\chi}$ is a parameter measuring the degree of wage indexation. When $\tilde{\chi}$ equals 0 , there is no wage indexation. When $\tilde{\chi}$ equals 1 , there is full wage indexation to past consumer price inflation. In general, $\tilde{\chi}$ can take any value between 0 and 1 .

Each variety of final goods is produced by a single firm in a monopolistically competitive environment. Each firm $i \in[0,1]$ produces output using as factor inputs capital services, $k_{i t}$, and labor services, $h_{i t}$. The production technology is given by

$$
z_{t} k_{i t}^{\theta} h_{i t}^{1-\theta}-\psi
$$

where the parameter $\theta$ lies between 0 and 1 . The variable $z_{t}$ denotes an aggregate, exogenous, and stochastic productivity shock whose law of motion is given by

$$
\ln z_{t}=\rho_{z} \ln z_{t-1}+\epsilon_{t}^{z}
$$


where $\rho_{z} \in(-1,1)$, and $\epsilon_{t}^{z}$ is an i.i.d. innovation with mean zero, standard deviation $\sigma_{\epsilon^{z}}$, and bounded support. The parameter $\psi>0$ introduces fixed costs of operating a firm in each period. It implies that the production function exhibits increasing returns to scale. We model fixed costs to ensure a realistic profit-to-output ratio in steady state.

Aggregate demand for good $i$, which we denote by $y_{i t}$, is given by

$$
y_{i t}=\left(P_{i t} / P_{t}\right)^{-\eta} y_{t}
$$

where

$$
y_{t} \equiv c_{t}\left[1+\phi_{1} v_{t}+\phi_{2} / v_{t}-2 \sqrt{\phi_{1} \phi_{2}}\right]+i_{t}+g_{t}+\left[\gamma_{1}\left(u_{t}-1\right)+\gamma_{2} / 2\left(u_{t}-1\right)^{2}\right] k_{t}
$$

denotes aggregate absorption. The variable $g_{t}$ denotes government consumption of the composite good in period $t$.

We rationalize a demand for money by firms by imposing that wage payments be subject to a cash-in-advance constraint of the form:

$$
m_{i t}^{f} \geq \nu w_{t} h_{i t}
$$

where $m_{i t}^{f}$ denotes the demand for real money balances by firm $i$ in period $t$ and $\nu \geq 0$ is a parameter indicating the fraction of the wage bill that must be backed with monetary assets. The presence of a working-capital requirement introduces a financial cost of labor that is increasing in the nominal interest rate. We note also that because all firms face the same factor prices and because they all have access to the same production technology that is linearly homogeneous up to a constant term, marginal costs are identical across firms.

Prices are assumed to be sticky à la Calvo (1983) and Yun (1996). Specifically, each period $t \geq 0$ a fraction $\alpha \in[0,1)$ of randomly picked firms is not allowed to optimally set the nominal price of the good they produce. Instead, these firms index their prices to past 
inflation according to the rule $P_{i t}=P_{i t-1} \pi_{t-1}^{\chi}$. The interpretation of the parameter $\chi$ is the same as that of its wage counterpart $\tilde{\chi}$. The remaining $1-\alpha$ firms choose prices optimally.

\subsection{The Government}

Each period, the government consumes $g_{t}$ units of the composite good. We assume that the variable $g_{t}$ is exogenous and that its logarithm follows a first-order autoregressive process of the form

$$
\ln \left(g_{t} / \bar{g}\right)=\rho_{g} \ln \left(g_{t-1} / \bar{g}\right)+\epsilon_{t}^{g},
$$

where $\rho_{g} \in(-1,1)$ and $\bar{g}>0$ are parameters, and $\epsilon_{t}^{g}$ is an i.i.d. innovation with mean zero, standard deviation $\sigma_{\epsilon^{g}}$, and bounded support. The parameter $\bar{g}$ represents the nonstochastic steady-state level of government absorption. We assume that the government minimizes the cost of producing $g_{t}$. As a result, public demand for each variety $i \in[0,1]$ of differentiated goods $g_{i t}$ is given by $g_{i t}=\left(P_{i t} / P_{t}\right)^{-\eta} g_{t}$. A second source of government expenditures are transfer payments to households in the amount $n_{t}$, measured in units of the composite good. Like government consumption, transfers are assumed to be exogenous and to follow the law of motion

$$
\ln \left(n_{t} / \bar{n}\right)=\rho_{n} \ln \left(n_{t-1} / \bar{n}\right)+\epsilon_{t}^{n}
$$

where $\rho_{n} \in(-1,1)$ and $\bar{n}>0$ are parameters, and $\epsilon_{t}^{n}$ is an i.i.d. innovation with mean zero, standard deviation $\sigma_{\epsilon^{n}}$, and bounded support. The parameter $\bar{n}$ represents the nonstochastic steady-state level of government transfers.

The government levies labor, capital, and profit income taxes. It grants allowances for the costs of depreciation and variations in capacity utilization. Total tax revenues are then given by $\tau_{t} \equiv \tau_{t}^{k}\left[r_{t}^{k} u_{t}-a\left(u_{t}\right)-q_{t} \delta\right] k_{t}+\tau_{t}^{h} h_{t}^{d} w_{t}+\tau_{t}^{\phi} \phi_{t}$. The government issues money given in real terms by $m_{t} \equiv m_{t}^{h}+\int_{0}^{1} m_{i t}^{f} d i$. The fiscal authority covers deficits by issuing one-period, nominally risk-free bonds, $B_{t}$. The period-by-period budget constraint of the consolidated government is then given by $b_{t}-\left(R_{t-1} / \pi_{t}\right) b_{t-1}+m_{t}-m_{t-1} / \pi_{t}=g_{t}+n_{t}-\tau_{t}$. Letting 
$a_{t} \equiv R_{t} b_{t}+m_{t}$, we can write the government's budget constraint as

$$
\frac{a_{t}}{R_{t}}+m_{t}\left(1-R_{t}^{-1}\right)+\tau_{t}=\frac{a_{t-1}}{\pi_{t}}+g_{t}+n_{t}
$$

We assume that at time 0 the benevolent government has been operating for an infinite number of periods. In choosing optimal policy, the government is assumed to honor commitments made in the past. This form of policy commitment has been referred to as 'optimal from the timeless perspective' (Woodford, 2003).

A Ramsey equilibrium is defined as the competitive equilibrium that maximizes the lifetime utility of the representative agent. Technically, the difference between the usual Ramsey equilibrium concept and the one employed here is that here the structure of the optimality conditions associated with the Ramsey equilibrium is time invariant. By contrast, under the standard Ramsey equilibrium definition, the equilibrium conditions in the initial periods are different from those applying to later periods.

Our results concerning the business-cycle properties of Ramsey-optimal policy are comparable to those obtained in the existing literature under the standard definition of Ramsey optimality (e.g., Chari, Christiano, and Kehoe, 1995). The reason is that existing studies of business cycles under the standard Ramsey policy focus on the behavior of the economy in the stochastic steady state (i.e., they limit attention to the properties of equilibrium time series excluding the initial transition).

\subsection{Calibration}

We calibrate the model at a quarterly frequency. Most of the parameter values are taken from the empirical work of Christiano, Eichenbaum, and Evans (2005) and Altig et al. (2004). These papers estimate the structural parameters of the model presented in the previous section using postwar U.S. data. A notable exception to this rule is the calibration of the degree of indexation in product prices and wages. The reason is that in those papers 
the parameters governing the degree of indexation are not estimated. They simply assume full indexation of all prices to past product price inflation. Instead, we draw from the econometric work of Cogley and Sbordone (2004) and Levin et al. (2005) who find no evidence of indexation in product prices. We therefore set $\chi=0$. At the same time, Levin et al. estimate a high degree of indexation in nominal wages. We therefore assume that $\tilde{\chi}=1$.

Table 1 gathers the values of the deep structural parameters of the model implied by our calibration strategy.

A more detailed description of this strategy is contained in the expanded version of this paper (Schmitt-Grohé and Uribe, 2005b).

\section{The Ramsey Steady State}

Consider the long-run state of the Ramsey equilibrium in an economy without uncertainty. We refer to this state as the Ramsey steady state. Note that the Ramsey steady state is in general different from the allocation/policy that maximizes welfare in the steady state of a competitive equilibrium.

Table 2 displays the Ramsey steady-state values of inflation, the nominal interest rate, and labor and capital income tax rates under a number of environments of interests.

The figures reported in the table correspond to the exact numerical solution to the steadystate of the Ramsey problem.

\subsection{The Optimal Level of Inflation}

Consider first the case in which profits are taxed at the same rate as income from capital $\left(\tau_{t}^{\phi}=\tau_{t}^{k}\right.$ for all $\left.t\right)$. In this case, the Ramsey planner chooses to conduct monetary policy in such a way as to nearly stabilize the price level. The optimal inflation rate is 18 basis 
points per year (line 1 of table 2). It is worth noting that, although small, the steady-state inflation rate is positive. This finding is somewhat surprising, for a well-known result in the context of simpler versions of the new Keynesian model is that the Ramsey steady-state level of inflation is negative and lies between the one called for by the Friedman rule and the one corresponding to full price stabilization. In calibrated example economies, the optimal deflation rate is, however, small (see, for instance, Schmitt-Grohé and Uribe, 2004a; and Khan, et al., 2003). In these simpler models the optimal inflation rate is determined by the tradeoff between minimizing the opportunity cost of holding money (which requires setting the inflation rate equal to minus the real interest rate) and minimizing price dispersion arising from nominal rigidities (which requires setting inflation at zero). Clearly, our finding of a positive inflation rate suggests that in the medium-scale economy we study in this paper there must be an additional tradeoff that the Ramsey planner faces in setting the rate of inflation. To make the presence of the third tradeoff nitid, we consider the case of indexation of product prices to lagged inflation, $\chi=1$ (line 2 of table 2 ). In this case, the long-run distortions stemming from nominal rigidities are nil. (Recall that in our calibration nominal wages are fully indexed, i.e., $\tilde{\chi}=1$.) Therefore, in this case there is no tradeoff between the sticky-price and money-demand frictions. In the absence of any additional tradeoffs, one should expect the Friedman rule to be optimal in this case. However, line 2 of table 2 shows that under long-run price flexibility, the optimal rate of inflation is 4.6 percent per year, a value even further removed from the Friedman rule than the one that is optimal under no indexation in product markets (line 1 of table 2).

The third tradeoff turns out to originate in the presence of government transfer payments to households, $n_{t}$. Line 3 of table 2 shows that under full indexation and in the absence of government transfers, the Friedman rule emerges as the optimal monetary policy. That is, the nominal interest rate is zero and the inflation rate is negative and equal to the rate of discount in absolute value. The reason why lump-sum government transfers induce positive inflation is that from the viewpoint of the Ramsey planner they represent pure rents accruing 
to households and as such can be taxed without creating a distortion. In the absence of a specific instrument to tax transfer income, the government chooses to tax this source of income indirectly when it is used for consumption. Specifically, in the model consumption purchases require money. As a result, a positive opportunity cost of holding money-i.e., a positive nominal interest rate - acts as a tax on consumption. ${ }^{2}$

Clearly, in the present model, if lump-sum transfers could be set optimally, they would be set at a negative value in a magnitude sufficient to finance government expenditures and output subsidies aimed at eliminating monopolistic distortions in product and factor markets. But in reality government transfers are positive and large. In the United States, they averaged 7 percent of GDP in the postwar era. Justifying this amount of government transfers as an optimal outcome lies beyond the scope of this paper. One obvious theoretical element that would introduce a rationale for positive government transfers would be the introduction of some form of heterogeneity across households.

Whether set optimally or not, government transfers must be financed. Comparing lines 1 and 4 of table 2 it follows that the government must increase the labor income tax rate by 12 percentage points to finance transfer payments of 7 percent of GDP. Thus, the economy featuring transfers is significantly more distorted than the one without transfers. Because, in general, optimal stabilization policy will depend on the average level of distortion present in the economy, it is of importance for the purpose of this paper to explicitly include transfers into the model. It is noteworthy that under the calibration shown in table 1 (particularly, under no indexation), allowing for transfers has virtually no effect on the steady-state Ramsey policy except for the level of the labor income tax rate. Specifically, comparing lines 1 and 4 of table 2 shows that removing transfers has virtually no bearing on the optimal rate of inflation and capital income taxation in the steady state.

We conclude that the tripodal tradeoff that determines the Ramsey long-run rate of inflation is resolved in favor of price stability. In this sense, the nominal price friction appears to dominate the money demand friction and the transfer-taxation motive in shaping optimal monetary policy in the long run. 


\subsection{Optimal Tax Rates}

Consider first the economy where profit income are taxed at 100 percent $\left(\tau_{t}^{\phi}=1\right)$. In this case, shown in line 5 of table 2, the Ramsey plan calls for subsidizing capital at the rate of 44.3 percent in the deterministic steady state. It is well known from the work of Judd (2002) that in the presence of imperfect competition in product markets, the markup of prices over marginal costs introduces a distortion between the private and the social returns to capital that increases exponentially over the investment horizon. As a result, optimal policy calls for eliminating this distortion by setting negative capital income tax rates. To gain insight into the nature of the capital income subsidy, note that in steady state the private return to investment is given by $\left(1-\tau^{k}\right)\left(u F_{k} / \mu-\delta-a(u)\right)$, where $\mu$ denotes the steady-state markup, $u F_{k}$ denotes the marginal product of capital, $\delta$ denotes the depreciation rate, and $a(u)$ denotes the cost of utilizing capital at the rate $u$. The social return to capital is given by $u F_{k}-\delta-a(u)$. Equating the private and social returns to investment requires setting $\tau^{k}$ so that

$$
\left(1-\tau^{k}\right)\left(u F_{k} / \mu-\delta-a(u)\right)=u F_{k}-\delta-a(u)
$$

Because in the presence of market power in product markets, the markup is greater than unity $(\mu>1)$, it follows that $\tau^{k}$ must be negative. Using the fact that in the steady state $1=\beta\left[\left(1-\tau^{k}\right)\left(u F_{k} / \mu-\delta-a(u)\right)+1\right]$, we can write the above expression as:

$$
1-\tau^{k}=\mu\left[\frac{\left(\beta^{-1}-1\right)}{\beta^{-1}-1-(\mu-1)(\delta+a(u))}\right]
$$

It is clear from this expression that if the depreciation rate is zero $(\delta=0)$, and capacity utilization is fixed at unity (so that $a(u)=0$ ), then the optimal capital income tax rate is equal to the net markup in absolute value. The case of zero depreciation and constant capacity utilization is the one considered in Judd (2002). ${ }^{3}$ We find that the introduction 
of depreciation in combination with a depreciation allowance, which is clearly the case of greatest empirical interest, magnifies significantly the size of the optimal capital subsidy. For instance, in our economy the markup is 20 percent, the depreciation rate is 7 percent per year, and the discount factor is 4 percent per year. In the case of no depreciation and fixed capacity utilization, the formula in equation (3) implies a capital subsidy equal in size to our assumed markup of 20 percent. However, with a conservative depreciation rate of 7 percent per year and fixed capacity utilization - which we induce by increasing $\gamma_{2}$ by a factor of $10^{5}$ - the optimal subsidy on capital income skyrockets to 85 percent (see line 6 of table 2). The reason for this tremendous rise in the size of the subsidy is that the government taxes the rate of return on capital net of depreciation, whereas the markup distorts the rate of return on capital gross of depreciation.

Allowing for variable capacity utilization (by setting $\gamma_{2}$ at its baseline value of 0.0685 ), reduces the capital subsidy from 85 percent (line 6 of table 2) to 44 percent (line 5 of table 2 ). The reason why the subsidy is smaller in this case is that $a(u)$ is negative, which results in a lower effective depreciation rate. ${ }^{4}$

An additional factor determining the size of the optimal subsidy on capital is the fiscal treatment of profits. The formula given in equation (3) applies when profits are taxed at a 100 percent rate. Consider instead the case in which profit income is taxed at the same rate as capital income $\left(\tau_{t}^{\phi}=\tau_{t}^{k}\right)$, which is assumed in lines 1-4 of table 2. Because profits are pure rents, the Ramsey planner has an incentive to confiscate them. This creates a tension between setting $\tau^{k}$ equal to 100 percent, so as to fully tax profits, and setting $\tau^{k}$ at the negative value that equates the social and private returns to investment. This explains why when the Ramsey planner is constrained to tax profits and capital income at the same rate, the optimal subsidy to capital is 6.3 percent, a number much smaller than the 85 percent implied by equation (3).

Line 7 of table 2 displays the case in which the Ramsey planner is constrained to follow an income tax policy. That is, fiscal policy stipulates $\tau_{t}^{h}=\tau_{t}^{k}=\tau_{t}^{\phi}$. Not surprisingly, the 
optimal income tax rate falls in between the values of the labor and capital income tax rates that are optimal when the fiscal authority is allowed to set these tax rates separately (line 5 of table 2). The optimal rate of inflation under an income tax is small, half a percent per annum, and not significantly different from the one that emerges when taxes can vary across income sources. The reason why the inflation rate is higher than in the baseline case is that in this way the Ramsey planner can tax labor at a higher rate than capital, a point we discuss in detail later.

\section{Ramsey Dynamics Under Income Taxation}

In this section, we study the business-cycle implications of Ramsey-optimal policy when tax rates are restricted to be identical across all sources of income. Specifically, we study the case in which,

$$
\tau_{t}^{h}=\tau_{t}^{k}=\tau_{t}^{\phi} \equiv \tau_{t}^{y}
$$

for all $t$, where $\tau_{t}^{y}$ denotes the income tax rate.

We approximate the Ramsey equilibrium dynamics by solving a first-order approximation to the Ramsey equilibrium conditions. There is evidence that first-order approximations to the Ramsey equilibrium conditions deliver dynamics that are fairly close to those associated with the exact solution. For instance, in Schmitt-Grohé and Uribe (2004b) we compute the exact solution to the Ramsey equilibrium in a flexible-price dynamic economy with money, income taxes, and monopolistic competition in product markets. In Schmitt-Grohé and Uribe (2004a) we then compute the solution to the exact same economy using a first-order approximation to the Ramsey equilibrium conditions. We find that the exact solution is not significantly different from the one based on a first-order approximation.

It has also been shown in the context of environments with fewer distortions than the medium-scale macroeconomic model studied here that a first-order approximation to the Ramsey equilibrium conditions implies dynamics that are very close to the dynamics asso- 
ciated with a second-order approximation to the Ramsey system. Specifically, in SchmittGrohé and Uribe (2004a) we establish this result using a dynamic general equilibrium model with money, income taxes, sticky prices in product markets, and imperfect competition. ${ }^{5}$

Table 3 displays the standard deviation, serial correlation, and correlation with output of a number of macroeconomic variables of interest in the Ramsey equilibrium with income taxation.

In computing these second moments, all structural parameters of the model take the values shown in table 1. Second moments are calculated using Monte Carlo simulations. We perform 1000 simulations of 200 quarters each. For each simulation, we compute second moments and then average these figures over the 1000 simulations.

An important result that emerges from table 3 is that under the optimal policy regime inflation is remarkably stable over the business cycle. This result is akin to the one derived in the context of models with a single distortion, namely sticky product prices and no fiscal considerations (Goodfriend and King, 1997 among many others). In the canonical Neo Keynesian model studied in Goodfriend and King, the optimality of price stability is a straightforward result. For in that environment, the single cause of inefficiencies is price dispersion due to exogenous impediments to the adjustment of nominal prices. By contrast, the medium-scale model studied here features, in addition to price stickiness, distortions that in isolation would call for a highly volatile inflation rate under the Ramsey plan.

First, the fact that the government does not have access to lump-sum taxation provides an incentive for the Ramsey planner to use unexpected variations in the inflation rate as a capital levy on private holdings of nominal assets to finance innovations in the fiscal deficit. In effect, Chari et al. (1991) show in the context of a flexible-price model that the optimal rate of inflation volatility is extremely high (above 10 percent per year). ${ }^{6}$ So in setting the optimal level of inflation volatility, the Ramsey planner faces a tradeoff between using inflation as a capital levy and minimizing the dispersion of nominal prices. For plausible 
calibrations, this tradeoff has been shown to be resolved overwhelmingly in favor of price stability. For example, Schmitt-Grohé and Uribe (2004a) show within a sticky-price model with distorting taxes that a miniscule amount of price stickiness suffices to induce the Ramsey planner to abandon the use of inflation as a fiscal instrument in favor of virtually complete price stability. Table 3 shows that this result survives in the much richer environment studied here, featuring a relatively large number of nominal and real rigidities.

Second, the fact that our model features sticky wages introduces an incentive for the Ramsey planner to adjust prices so as to bring about efficient real wage movements. As will be shown shortly, nominal wage stickiness in isolation calls for the Ramsey inflation rate to be highly volatile.

With the inflation rate not playing the role of absorber of fiscal shocks, the Ramsey planner must finance fiscal disturbances via deficits or changes in tax rates or both. Table 3 shows that in our model the role of shock absorber is picked up to a large extent by fiscal deficits (i.e., by adjustments in the level of public debt). Total government liabilities, $a_{t}$, are relatively volatile and display a near-unit-root behavior. The standard deviation of government liabilities is 4.4 percent per quarter and the serial correlation is 0.99 in our simulated sample paths. By contrast tax rates do not vary much over the business cycle. The Ramsey planner is able to implement tax smoothing by allowing public liabilities to vary in response to fiscal shocks.

\subsection{Nominal Rigidities and Optimal Policy}

Table 4 presents the effects of changing the degree of wage or price stickiness on the behavior of policy variables.

Panel A considers the case of no transfers $\left(n_{t}=0\right.$ for all $\left.t\right)$. This case is of interest because it removes the government's incentive to tax transfers through long-run inflation, making the economy more comparable to existing related studies. When product and factor 
prices are fully flexible $(\alpha=\tilde{\alpha}=0)$, the optimal policy features high inflation volatility (5.8 percentage points per quarter at an annual rate) and relatively stable tax rates, with a standard deviation of 0.1 percent. In this case, as discussed earlier, variations in inflation are used as a state-contingent tax on nominal government liabilities, allowing the Ramsey planner to smooth taxes. Public debt is stationary with a serial correlation of 0.84 .

When prices are sticky but wages are flexible $(\alpha=0.6$ and $\tilde{\alpha}=0)$, the optimal inflation volatility falls dramatically from 5.8 percent to less than 0.1 percent. Because prices are costly to adjust, the Ramsey planner relinquishes the use of surprise inflation as a fiscal shock absorber. Instead, he uses variations in fiscal deficits and some small adjustments in the income tax rate to guarantee fiscal solvency. This practice results in a drastic increase in the serial correlation in government assets, which become a (near) random-walk process. These effects of price stickiness on optimal monetary and fiscal policy are known to emerge in the context of models without capital and fewer nominal and real frictions (see, for instance, Schmitt-Grohé and Uribe, 2004a).

In the benchmark case, where both prices and wages are sticky $(\alpha=0.6$ and $\tilde{\alpha}=0.64)$, inflation is more volatile than under product price stickiness alone. As stressed by Erceg et al. (2000) in the context of a much simpler model without a fiscal sector or capital, the reason for the increased volatility of inflation in the case of both price and wage stickiness relative to the case of price stickiness alone, is that the central bank faces a tradeoff between minimizing relative product price dispersion and minimizing relative wage dispersion. Quantitatively, however, this tradeoff appears to be resolved in favor of minimizing product price dispersion rather than wage dispersion. In effect, under price stickiness alone, the volatility of inflation is 0.09 percent, whereas under wage stickiness alone it is 5.8 percent. $^{7}$ When both nominal rigidities are present, the optimal inflation volatility falls in between these two values, but, at 1.1 percent, is much closer to the lower one. Interestingly, this result obtains even if one assumes that nominal wages are not indexed to past inflation $(\tilde{\chi}=0)$. In this case, the optimal inflation volatility is 0.9 percent, which is even lower than under full wage indexation 
(see table 5 and the discussion around it). We note that indexation to past consumer price inflation, being an arbitrary scheme, may not necessarily be welfare improving in our model.

Panel B of table 4 considers the baseline case of positive transfers. All of the results obtained under the assumption of no transfers carry over to the economy with transfers. ${ }^{8}$ In particular, it continues to be the case that inflation stability is the dominant characteristic of Ramsey-optimal policy. It is of interest that the optimality of inflation stability obtains in spite of the fact that nominal wages are set optimally less frequently than are product prices. As will be clear shortly, the fact that wages are assumed to be fully indexed to past inflation is not the crucial factor behind this result. Panel B of table 4 presents a further robustness check of our main result. It displays the case in which wages are reoptimized every 8 quarters $(\tilde{\alpha}=0.87)$ instead of every 3 quarters $(\tilde{\alpha}=0.64)$, as in the baseline calibration. In this case the optimal inflation volatility is 1.8 percent. This number is higher than the corresponding number under the baseline calibration (1.1 percent), but still relatively small. ${ }^{9}$

The reason why we pick a value of 0.87 for the parameter $\tilde{\alpha}$ in our robustness test is that this number makes our model of wage rigidities comparable with the formulation in which wage stickiness results in employment heterogeneity across households introduced by Erceg et al. (2000). In effect, it can shown that up to first-order both specifications give rise to a Phillips curve relating current wage inflation to future expected wage inflation and the wage markup. The difference between the two specifications is that the coefficient on the wage markup is smaller in the Erceg et al. model. A value of $\tilde{\alpha}$ equal to 0.87 ensures that the coefficient on the wage markup in our model is equal to that implied by the Erceg et al. model. ${ }^{10}$

We close this section with a digression. One may wonder why in the case of fully flexible product and factor prices and no transfers $\left(\alpha=\tilde{\alpha}=n_{t}=0\right)$, the Friedman rule fails to be Ramsey optimal. The reason is that under an income-tax regime a positive nominal interest rate allows the Ramsey planner to effectively tax labor at a higher rate than capital. The planner engineers this differential effective tax rate by exploiting the fact that firms are 
subject to a cash-in-advance constraint on the wage bill. The reason why it is optimal for the planner to tax labor at a higher rate than capital is clear from our analysis of the Ramsey steady state in the case in which labor and capital income can be taxed at different rates (section 3). In this case, the Ramsey planner selects to subsidize capital and to tax labor. Under the income-tax regime studied here, the planner is unable to set different tax rates across sources of income. But he does so indirectly by levying an inflation tax on labor.

In the flexible-price economy, the inflation bias introduced by the combination of an income tax and a cash-in-advance constraint on wages is large, above 4 percent per year. If in an economy without nominal rigidities and without government transfers one were to lift the cash-in-advance constraint on wage payment by setting the parameter $\nu$ equal to zero, the Friedman rule would reemerge as the Ramsey outcome. But the inflation bias introduced by government transfers and the working capital constraint is small in an economy with sticky prices. In effect, under our assumed degree of price stickiness $(\alpha=0.6)$, the steady-state level of inflation falls from 0.51 percent per annum in the economy with transfers and a workingcapital constraint on wage payments to -0.19 percent in an economy without transfers and without a working-capital constraint. We conclude that in our model, the dominant force determining the long-run level of inflation is not the presence of government transfers, nor the demand for money by firms, nor the demand for money by households, but rather the existence of long-run frictions in the adjustment of nominal product prices.

\subsection{Indexation and Optimal Policy}

An important policy implication of our analysis of optimal fiscal and monetary policy in a medium-scale model under income taxation is the desirability of price stability. Because our benchmark calibration assumes full indexation in factor prices but no indexation in product prices, one may worry that our central policy result may be driven too much by the assumed indexation scheme. But this turns out not to be the case.

Consider a symmetric indexation specification in which neither factor nor good prices are indexed $(\chi=\tilde{\chi}=0)$. This case is shown in line 1 of table 5 . 
In the non-indexed economy the Ramsey plan calls for even more emphasis on price stability than in the environment with factor price indexation. The mean and standard deviation of inflation both fall from 0.51 and 1.1, respectively, in the economy with wage indexation to 0.11 and 0.94 in the economy without any type of indexation. The reason why the average inflation rate is lower in the absence of indexation is that removing wage indexation creates an additional source of long-run inefficiency stemming from inflation, namely, wage dispersion. The reason why inflation volatility also falls when one removes wage indexation is less clear. We simply note, as we did before, that the indexation scheme assumed here, namely indexing to past price inflation, being arbitrary, may or may not be welfare improving in the short run.

Consider now the case that prices are fully indexed but wages are not $(\chi=1$ and $\tilde{\chi}=0$ ). If our main result, namely the optimality of inflation stabilization, was driven by our indexation assumption, then the indexation scheme considered now would stack the deck against short-run price stability. Line 2 of table 5 shows that even when prices are indexed and wages are not, the Ramsey plan calls for the same low level of inflation volatility as under the reverse indexation scheme considered in the benchmark economy (line 3 of table 5). The reason is that if the planner were to move prices around over the business cycle so as to minimize the distortions introduced by nominal wage stickiness, then such price movements still would lead to important inefficiencies in the product market because prices although indexed are still sticky. Indexation removes the distortions associated with nominal rigidities only in the long run, not necessarily in the short run.

The fact that indexation removes the long-run inefficiencies associated with nominal product and factor price dispersion due to price stickiness is illustrated in line 4 of table 5, displaying the case of indexation in both product and factor markets. The Ramsey-optimal mean inflation rate is in this case 17 percent per year. This large number is driven by two 
fiscal policy factors identified earlier in this paper: high inflation allows the Ramsey planner to tax transfers indirectly and at the same time provides an opportunity to tax labor income at a higher rate than capital income.

\section{Optimized Policy Rules}

Ramsey outcomes are mute on the issue of what policy regimes can implement them. The information on policy one can extract from the solution to the Ramsey problem is limited to the equilibrium behavior of policy variables such as tax rates and the nominal interest rate. But this information is in general of little use for central banks or fiscal authorities seeking to implement the Ramsey equilibrium. Specifically, the equilibrium process of policy variables in the Ramsey equilibrium is a function of all of the states of the Ramsey equilibrium. These state variables include all of the exogenous driving forces and all of the endogenous predetermined variables. Among this second set of variables are past values of the Lagrange multipliers associated with the constraints of the Ramsey problem. Even if the policymaker could observe the state of all of these variables, using the equilibrium process of the policy variables to define a policy regime would not guarantee the Ramsey outcome as the competitive equilibrium. The problem is that such a policy regime could give rise to multiple equilibria.

In this section, we do not attempt to resolve the issue of what policy implements the Ramsey equilibrium in the medium-scale model under study. Rather, we focus on finding parameterizations of monetary and fiscal rules that satisfy the following 3 conditions: (a) They are simple, in the sense that they involve only a few observable macroeconomic variables; (b) They guarantee local uniqueness of the rational expectations equilibrium; and (c) They minimize some distance (to be specified shortly) between the competitive equilibrium they induce and the Ramsey equilibrium. We refer to rules that satisfy criteria (a) and (b) as implementable. We refer to implementable rules that satisfy criterion (c) as optimized rules. $^{11}$ 
We define the distance between the competitive equilibrium induced by an implementable rule and the Ramsey equilibrium as follows. Let $I R_{T, S, Y}^{R}$ denote the impulse response function associated with the Ramsey equilibrium of length $T$ quarters, for shocks in the set $S$, and variables in the set $Y$. Similarly, let $I R_{T, S, Y}^{C E}$ denote the impulse responses associated with the competitive equilibrium induced by a particular policy rule. Let $x \equiv \operatorname{vec}\left(I R_{T, S, Y}^{R}-\right.$ $\left.I R_{T, S, Y}^{C E}\right)$. Then, we define the distance between the Ramsey equilibrium and the competitive equilibrium associated with a particular implementable rule as $x^{\prime} x$.

An alternative definition of the distance between the competitive equilibrium induced by an implementable rule and the Ramsey equilibrium is given by the difference in the associated welfare levels. This definition of an optimized rule is equivalent to selecting policy-rule coefficients within the set of implementable rules so as to maximize the level of welfare associated with the resulting competitive equilibrium. We adopt this definition in Schmitt-Grohé and Uribe $(2004 c, e)$. In general, a policy rule that is optimal under this definition will not coincide with the one that is optimal according to criteria (a), (b), and (c). It is clear, however, from the quantitative welfare analysis reported later in this section that the gains from following such a strategy in lieu of the one adopted here are small.

In the present analysis, we take as reference the Ramsey equilibrium under the restriction of an income tax. We compute impulse response functions from a first-order accurate approximation to the Ramsey and competitive equilibria. We set the length of the impulse response function at 20 quarters $(T=20)$. The set of shocks is given by the three shocks that drive business cycles in the model presented above, productivity, government consumption, and government transfers shocks. That is, $S=\left\{z_{t}, g_{t}, n_{t}\right\}$. Finally, we include in the set $Y 17$ endogenous variables. Up to first order, all variables listed in the definition of a competitive equilibrium given in the expanded version of this paper can be obtained as a linear combination of the elements of the sets $Y$ and $S$. Of course, adding variables to the set $Y$ would not be in general inconsequential, for it would amount to altering the weights 
assigned to each impulse response in the criterion that is minimized here. However, as will be clear from the discussion that follows, expanding the set $Y$ or altering the weights given to each individual variable would result at best in negligible welfare gains.

The family of rules that we consider here consists of an interest-rule and a tax-rate rule. In the interest-rate rule, the nominal interest rate depends linearly on its own lag, the rates of price and wage inflation, and the log deviation of output from its steady state value. The tax-rate rule features the tax rate depending linearly on its own lag and log deviations of government liabilities and output from their respective steady-state values. Formally, the interest-rate and tax-rate rules are given by

$$
\ln \left(R_{t} / R^{*}\right)=\alpha_{\pi} \ln \left(\pi_{t} / \pi^{*}\right)+\alpha_{W} \ln \left(\pi_{t}^{W} / \pi^{*}\right)+\alpha_{y} \ln \left(y_{t} / y^{*}\right)+\alpha_{R} \ln \left(R_{t-1} / R^{*}\right)
$$

and

$$
\tau_{t}^{y}-\tau^{y *}=\beta_{a} \ln \left(a_{t-1} / a^{*}\right)+\beta_{y} \ln \left(y_{t} / y^{*}\right)+\beta_{\tau} \ln \left(\tau_{t-1}^{y}-\tau^{y *}\right)
$$

The target values $R^{*}, \pi^{*}, y^{*}, \tau^{y *}$, and $a^{*}$ are assumed to be the Ramsey steady-state values of their associated endogenous variables, given in the second column of table 3 . The variable $\pi_{t}^{W} \equiv W_{t} / W_{t-1}$ denotes wage inflation. It follows that in our search for the optimized policy rule, we pick 7 parameters so as to minimize the Euclidean norm of the vector $x$ containing 1020 elements. We set the initial impulse equal to 1 standard deviation of the innovation in the corresponding shock. That is, for impulse responses associated with shocks $z_{t}, g_{t}$, and $n_{t}$, the initial impulse is given by $\sqrt{\frac{\sigma_{\epsilon^{z}}^{2}}{\left(1-\rho_{z}^{2}\right)}}, \sqrt{\frac{\sigma_{\epsilon g}^{2}}{\left(1-\rho_{g}^{2}\right)}}$, and $\sqrt{\frac{\sigma_{\epsilon}^{2}}{\left(1-\rho_{n}^{2}\right)}}$, respectively.

The optimized rule is given by

$$
\ln \left(R_{t} / R^{*}\right)=0.37 \ln \left(\pi_{t} / \pi^{*}\right)-0.16 \ln \left(\pi_{t}^{W} / \pi^{*}\right)-0.06 \ln \left(y_{t} / y^{*}\right)+0.55 \ln \left(R_{t-1} / R^{*}\right)
$$

and

$$
\tau_{t}^{y}-\tau^{y *}=-0.06 \ln \left(a_{t-1} / a^{*}\right)+0.02 \ln \left(y_{t} / y^{*}\right)+1.88 \ln \left(\tau_{t-1}^{y}-\tau^{y *}\right) .
$$


The optimized interest-rate rule turns out to be passive, with the sum of the productprice and wage inflation coefficients less than unity. Under this rule, variation in aggregate activity do not trigger a monetary policy response, as can be seen from the fact that the output coefficient is close to zero. The optimized monetary rule exhibits interest rate inertia implying long-run reactions to deviations of inflation from target twice the size of the shortrun response.

The optimized tax-rate rule calls for a mute response to variations in output or government liabilities. In addition, it is superinertial with a coefficient on lagged tax rates of about 2. In equilibrium, this rule induces tax rates that are virtually constant over the business cycle.

\subsection{Welfare Under the Optimized Rule}

We measure the welfare cost of a particular monetary/fiscal policy specification vis à vis the Ramsey policy as the increase in consumption needed to make a representative consumer indifferent between living in an economy where the particular monetary/fiscal policy considered is in place and an economy where the government follows the Ramsey policy. The welfare cost is computed conditional on the initial state of the economy being the deterministic steady state of the Ramsey equilibrium. ${ }^{12}$ In computing welfare costs, we solve the model up to second-order of accuracy. In particular, we use the perturbation method and computer algorithm developed in Schmitt-Grohé and Uribe (2004d).

Applying this definition to evaluate the welfare cost of following the optimized policy rules given in equations (4) and (5) instead of implementing the Ramsey-optimal policy, we obtain a cost of 0.017 percent of the Ramsey consumption process. Using figures for personal consumption expenditures per person in the United States in 2003, the welfare cost amounts to 4.42 dollars per person per annum. 


\subsection{Ramsey and Optimized Impulse Responses}

To provide a sense of how close the dynamics induced by the Ramsey policy and the optimized rule are, in this section we present theoretical impulse responses to the three shocks driving business cycles in our model economy. Figure 1 displays impulse response functions to a one-standard-deviation increase in productivity $\left(\ln z_{1}=1.2\right.$ percent). Solid lines correspond to the Ramsey equilibrium, and broken lines correspond to the optimized policy rules.

Remarkably, in response to an increase in productivity, hours worked fall (indeed more than one for one). The reason for this sharp decline in labor effort is the presence of significant costs of adjustment in investment and consumption. Notice that neither consumption nor investment move much on impact. As a result, the increase in productivity must be accompanied by an increase in leisure large enough to ensure that output remains little changed on impact. The contraction in hours following a positive productivity shock is in line with recent econometric studies using data from the U. S. economy (see, for example, Galí and Rabanal, 2004).

The equilibrium dynamics of endogenous nonpolicy variables induced by the optimized policy rules mimic those associated with the Ramsey economy quite well. Surprisingly, these responses are induced with settings for the policy variables that are remarkably different from those associated with the Ramsey equilibrium. In particular, the response of the income tax rate is virtually flat in the competitive equilibrium whereas under the Ramsey policy tax rates increase sharply initially and then quickly fall to below-average levels. At the same time, the Ramsey planner responds to the productivity shock by tightening money market conditions, whereas the policy rule calls for a significant easing. It follows that the initial deceleration in inflation is a not a consequence of the monetary policy action - which is expansionary - but rather a reaction to forces that are fiscal in nature. In effect, the optimized rule leaves the income tax rate unchanged. At the same time output is expected to increase, so that the expected value of tax revenues increases. As a result a higher level of government liabilities 
can be supported in equilibrium. The initial deflation, therefore, serves as a mechanism to boost the real value of outstanding government liabilities.

Figures 2 and 3 display impulse responses to a government spending shock and a government transfer shock, respectively.

In both cases, the size of the initial impulse equals one standard deviation of the shock (3.2 percent for the government spending shock, and 3.5 percent for the government transfer shock). The equilibrium dynamics under the optimized policy rule appear to mimic those associated with the Ramsey policy not as closely as in the case of a productivity shock. This is understandable, however, if one takes into account that these two shocks explain only a small fraction of aggregate fluctuations. In effect, productivity shocks alone explain over 90 percent of variations in aggregate activity under the Ramsey policy. The optimization estimation procedure therefore naturally assigns a smaller weight on fitting the dynamics induced by $g_{t}$ and $n_{t}$.

\subsection{Ramsey Policy With A Single Instrument}

In this section we ask how optimal policy changes if the government is restricted to setting optimally either monetary or fiscal policy but not both. Of course, the answer to this question may in principle be sensitive to the details of the policy that is assumed to be set non optimally.

We consider two cases. In one, fiscal policy is set optimally, while the monetary authority follows a simple Taylor rule with an inflation coefficient of 1.5 , that is, $R_{t} / R=\left(\pi_{t} / \pi\right)^{1.5}$. Here, the parameters $R$ and $\pi$ correspond to the steady-state values of $R_{t}$ and $\pi_{t}$ in the Ramsey equilibrium with optimal monetary and fiscal policy. We pick this particular specification for monetary policy because it has been widely used in related empirical and theoretical studies. The other policy regime we consider is one in which monetary policy is determined in a Ramsey optimal fashion but fiscal policy consists in keeping real government liabilities 
constant over time. That is, $a_{t}=a$, where $a$ denotes the deterministic steady-state value of $a_{t}$ in the Ramsey equilibrium with optimal fiscal and monetary policy. Our choice of fiscal policy in this case is motivated by the fact that in most existing studies of monetary policy it is typically assumed implicitly or explicitly that the fiscal authority ensures fiscal solvency under all possible (equilibrium and off-equilibrium) paths of the price level.

Table 6 displays second moments of endogenous variables of interest and welfare of the representative agent conditional on the initial state being the Ramsey steady state with optimal fiscal and monetary policy.

The economy with nonoptimal fiscal policy is significantly more volatile than the economy with nonoptimal monetary policy. The reason is that in the economy with nonoptimal fiscal policy the government is forced to adjust tax rates over the business cycle so as to ensure constancy of real public liabilities. Higher volatility of real variables, however, is not associated with lower welfare. On the contrary, the welfare cost of not being able to conduct optimal monetary policy are much larger than the welfare cost of not being able to conduct optimal fiscal policy.

\section{Capital and Labor Taxation}

In this section, we characterize dynamic Ramsey policy under the assumption that the fiscal authority has access to three tax instruments, taxes on capital income $\left(\tau_{t}^{k}\right)$, taxes on labor income $\left(\tau_{t}^{h}\right)$, and taxes on pure profits $\left(\tau_{t}^{\phi}\right)$. Clearly, the optimal tax rate on profits is 100 percent. We thus set $\tau_{t}^{\phi}=1$ for all $t$ for the remainder of the section.

We analyzed the Ramsey steady state of this economy earlier in section 3. As shown on line 5 of table 2 , in the Ramsey steady state the labor income tax rate is 38.2 percent and the capital subsidy is 44.3 percent. For the calibration shown in table 1, we find that the standard deviation of the capital income tax rate under the Ramsey policy is 148 percent. The natural 
reaction to this number is that in this economy the constraint that capital subsidies and taxes should be less than 100 percent will be frequently violated and in this regard the optimal policy makes little economic sense. ${ }^{13}$ Qualitatively, however, the intuition for why the volatility of the capital income tax is high is clear. Because capital is a predetermined state variable, unexpected variations in the capital income tax rate act as a nondistorting levy, which the fiscal authority uses to finance innovations in the government budget. The (population) serial correlation of capital tax rates is very close to zero at -0.07 . When capital income tax rates can play the role of a fiscal shock absorber, government liabilities no longer display the near random walk behavior as in the case of an income tax. In fact, the (population) serial correlation of $a_{t}$ now is only 0.6.

To put the number we obtain for the optimal volatility of $\tau_{t}^{k}$ into perspective, we use as a point of reference two simpler but related economies. First, Chari et. al. (1995), study optimal taxation in a standard real-business-cycle model with exogenous long-run growth and report a standard deviation of the capital income tax rate of 40 percentage points for the stochastic steady state of the Ramsey equilibrium. ${ }^{14}$

The second economy we study as a point of reference is a stationary version of the RBC model of Chari et al. (1995). We find that if one assumes no long-run growth in the Chari et al. economy, the standard deviation of capital income taxes shoots up to about 60 percent (assuming that the level of government assets in the steady state is the same as in the economy with growth). This result illustrates that relatively minor modifications in the economic environment can lead to drastic changes in the optimal volatility of capital income tax rates. Still, these values are not as high as the ones we find in our much more complex model economy. In what follows we complete the reconciliation of our finding with those available in the existing literature. 


\subsection{Time To Tax}

Two modifications to our medium-scale macroeconomic model allow us to drive the optimal volatility of capital tax rates down to a level that is comparable to the one that obtains in the standard real business cycle model without growth. First, the model studied by Chari et al. features no impediments to adjusting the level of investment over the business cycle, whereas our model economy incorporates significant investment adjustment costs. Lowering the investment adjustment cost parameter $\kappa$ by a factor of 1,000 reduces the optimal capital income tax volatility from 148 percent to 66 percent which is close to the volatility of the RBC model without growth. If in addition we assume that tax rates are set one period in advance, then the optimal capital tax volatility falls to 20 percent. The reason why adjustment costs induce a higher optimal volatility of the capital income tax is that investment adjustment costs make capital more akin to a fixed factor of production thereby making movements in the capital tax rate less distorting.

Second, the time unit in the Chari et al. model is one year. By contrast, the time unit in our model is one quarter. Our choice of a time unit is guided by the fact that we study optimal monetary policy as well as optimal fiscal policy. It is unrealistic to assume that the government adjusts monetary policy only once a year. For example, in the United States the FOMC meets every 8 weeks. At the same time, it is equally unrealistic to assume that tax rates change every quarter. One possible way to resolve this conflict is to continue to assume that the time unit is one quarter and to impose that tax rates are determined several quarters in advance, that is, that there are tax lags.

Figure 4 depicts the standard deviation of the capital income tax as a function of the number of tax lags.

It shows the results for the economy calibrated using the parameter values shown in table 1 . The graph illustrates that the optimal volatility of the capital income tax rate falls steadily with the number of tax lags. Under the assumption that tax rates are determined 
four quarters in advance, the optimal volatility of capital taxes is driven down to about 49 percentage points. This level of volatility is lower than the values obtained in a non-growing RBC model.

\subsection{Capital Tax Volatility and Cost of Varying Capacity Utiliza- tion}

Another difference between the simple RBC model of Chari et al. (1995) and the model studied here, is that our model economy incorporates variable capacity utilization. One may think that the presence of variable capacity utilization could induce lower capital income tax volatility. For in this case the effective stock of capital is no longer predetermined. As a result, one would expect that variations in the capital income tax rate should be more distorting and hence used less. It turns out, however, that the volatility of the capital income tax rate is not significantly affected when the cost of varying the intensity of capacity utilization falls (in our model, when $\gamma_{2}$ is reduced). For example, when we hold $\gamma_{1}$ constant and reduce $\gamma_{2}$ by a factor of 2, the optimal capital tax volatility increases from 149 percent to 153 percent.

\section{Conclusion}

We study Ramsey-optimal fiscal and monetary policy in a medium-scale model of the U.S. business cycle. The model features a rich array of real and nominal rigidities that have been identified in the recent empirical literature as salient in explaining observed aggregate fluctuations.

We find that price stability appears to be a central goal of optimal monetary policy. The optimal rate of inflation under an income tax regime is half a percent per year with a standard deviation of 1.1 percent. This result is somewhat surprising given that the model features a number of frictions that in isolation would call for a volatile rate of inflation-particularly nonstate-contingent nominal public debt, no lump-sum taxes, and sticky wages. 
Under an income-tax regime, the Ramsey-optimal income tax rate is quite stable, with a standard deviation of 1.1 percent around a mean of 30 percent. In addition, the Ramsey outcome features a near random walk in real public debt. Taken together, these results suggest that shocks to the fiscal budget are financed neither through surprise inflation (as in models with flexible nominal prices), nor through adjustments in the income tax rate, but rather through variations in the fiscal deficit. It follows that the Ramsey equilibrium has little resemblance to a world operating under a balanced-budget rule.

We show that simple monetary and fiscal rules implement a competitive equilibrium that mimics well the one induced by the Ramsey policy. These rules bring about welfare levels that are virtually identical to the ones associated with the Ramsey policy. The optimized interest-rate rule is passive, in the sense that the inflation coefficient is less than unity, and features a mute response to output and a mild degree of interest-rate inertia. At the same time, the optimized fiscal-policy rule is acyclical, in the sense that tax rates do not respond to changes in either output or the level of public debt. The fiscal rule is super inertial, with a coefficient on the lagged tax rate of about 2. Thus, for example an increase in taxes today is expected to be followed by further tax increases in the future. In equilibrium, this property of the fiscal rule renders tax rates virtually constant over the business cycle.

When the fiscal authority is allowed to tax capital and labor income at different rates, optimal fiscal policy is characterized by a large capital subsidy of over 40 percent with an enormous volatility of about 150 percent. The introduction of four quarters of time to tax brings this volatility down to 50 percent. While significant, this decline leaves the Ramseyoptimal capital-income-tax volatility impractically large.

The present study could be extended in a number of directions. One is to allow for a richer set of underlying shocks. Altig et al. (2004), for instance, allow for an additional productivity shock that is specific to the investment sector. Also, Smets and Wouters (2004) estimate a model with 10 shocks. Additionally, one could assume that the shocks driving business cycles are nonstationary, as in Altig et al. (2004). These extensions are of interest 
because optimal stabilization policy will in general be shaped by the number and nature of the exogenous shocks generating aggregate fluctuations. A word of caution, however, is in order before taking this route. In econometrically estimated versions of the model studied in this paper (or variations thereof), it is often the case that a large number of shocks is estimated as a byproduct. A number of these shocks are difficult to interpret economically. In effect, these shocks, to a large extent, represent simple econometric residuals reflecting the distance between model and data. A case in point are shocks to Euler equations or uncovered interest parity conditions. Before incorporating this type of residual as driving forces, it is perhaps more productive to give theory a chance to get closer to the data.

Possibly the most urgent step in this research program, however, is to characterize credible policy in large macroeconomic models. The Ramsey plans derived in the present study are time inconsistent, in the sense that at each point in time, a social planner that cares about the welfare of people from that moment on, has incentives to abandon promises made from a timeless perspective. In the past two decades, a growing literature in macroeconomics has been focusing on game-theoretic approaches to policy making. This literature focuses on identifying credible punishment schemes by the public should the government default on its policy promises. The aim is to find credible policies that maximize welfare. Thus far, applications of this line of research to fiscal and monetary policy has been limited to highly stylized, small-scale models. Extending the study of credible monetary and fiscal policy to large-scale models would be an important milestone for the theory of stabilization policy. 


\section{References}

Altig, David, Lawrence J. Christiano, Martin Eichenbaum, and Jesper Linde, "Firm-Specific Capital, Nominal Rigidities and the Business Cycle," mimeo, Northwestern University, November 28, 2004.

Benigno, Pierpaolo, and Michael Woodford, "Optimal Taxation in an RBC Model: A Linear-Quadratic Approach," NBER working paper No. 11029, January 2005.

Calvo, Guillermo A., "Staggered prices in a utility-maximizing framework," Journal of Monetary Economics 12, 1983, 383-98.

Calvo, Guillermo A. and Guidotti, Pablo E., "Indexation and Maturity of Government Bonds: An Exploratory Model," in Rudiger Dornbusch and Mario Draghi, eds., Public debt management: Theory and history, Cambridge: Cambridge University Press, 1990, $52-82$.

Calvo, Guillermo A. and Guidotti, Pablo E., "On the Flexibility of Monetary Policy: The Case of the Optimal Inflation Tax," The Review of Economic Studies 60, July 1993, 667-87.

Chari, V. V.; Christiano, Lawrence; and Kehoe, Patrick J., "Optimal Fiscal and Monetary Policy: Some Recent Results," Journal of Money, Credit, and Banking 23, August 1991, 519-539.

Chari, V. V., Lawrence J. Christiano, and Patrick J. Kehoe, "Policy Analysis in Business Cycle Models," in Thomas F. Cooley, Frontiers of Business Cycle Research, Princeton, Princeton University Press, 1995.

Christiano, Lawrence J., Martin Eichenbaum, and Charles L. Evans, "Nominal Rigidities and the Dynamic Effects of a Shock to Monetary Policy," Journal of Political Economy 113, February 2005, 1-45.

Chugh, Sanjay, "Optimal Fiscal and Monetary Policy With Sticky Wages and Sticky Prices," manuscript, Federal Reserve Board, May 2005.

Clarida, Richard, Jordi Galí, and Mark Gertler, "The Science of Monetary Policy: A New Keynesian Perspective," Journal of Economic Literature 37, 1999, 1661-1707. 
Cogley, Timothy, and Argia M. Sbordone, "A Search for a Structural Phillips Curve," manuscript, Federal Reserve Bank of New York, November 2004.

Erceg, Christopher J., Henderson, Dale W., and Levin, Andrew T., "Optimal Monetary Policy With Staggered Wage and Price Contracts," Journal of Monetary Economics 46, October 2000, 281-313.

Galí, Jordi, and Pau Rabanal, "Technology Shocks and Aggregate Fluctuations: How Well Does the RBC Model Fit Postwar U.S. Data?," in Mark Gertler and Kenneth Rogoff, eds., NBER Macroeconomics Annual 2004, Cambridge, MA: MIT Press, 2004, 225-288.

Goodfriend, Marvin, and Robert G. King, "The New Neoclassical Synthesis and the Role of Monetary Policy," in Ben S. Bernanke and Julio J. Rotemberg, eds., NBER Macroeconomics Annual 1997, Cambridge, MA: MIT Press, 1997, pp. 231-83.

Ireland, Peter, "A Small, Structural, Quarterly Model for Monetary Policy Evaluation," Carnegie-Rochester Conference Series on Public Policy 47, December 1997, 83-108.

Judd, Kenneth L., "Optimal Taxation in Dynamic Stochastic Economies: Theory and Evidence," manuscript, Hoover Institution, May 1992.

Judd, Kenneth L., "Capital-Income Taxation With Imperfect Competition," American Economic Review 92, May, 2002, 417-421.

Khan, Aubhik, Robert G. King, and Alexander Wolman, "Optimal Monetary Policy," Review of Economic Studies 70, October 2003, 825-860.

Kimball, Miles S., "The Quantitative Analytics of the Basic Neomonetarist Model," Journal of Money, Credit and Banking 27, November 1995, 1241-1277.

Levin, Andrew T., Alexei Onatski, John C. Williams, and Noah Williams, "Monetary Policy Under Uncertainty in Micro-Founded Macroeconometric Models," manuscript prepared for the NBER's Twentieth Annual Conference on Macroeconomics, March 31, 2005.

Lucas, Robert E. Jr. and Stokey, Nancy L., "Optimal Fiscal and Monetary Policy in an Economy Without Capital," Journal of Monetary Economics 12, 1983, 55-93. 
Rotemberg, Julio J., and Michael Woodford, "An Optimization-Based Econometric Framework for the Evaluation of Monetary Policy," in Bernanke, Ben S. and Julio J. Rotemberg, eds., NBER macroeconomics annual 1997, Cambridge and London: MIT Press, 1997, 297-346.

Schmitt-Grohé, Stephanie and Martín Uribe, "Optimal Fiscal and Monetary Policy under Sticky Prices," Journal of Economic Theory 114, February 2004(a), 198-230.

Schmitt-Grohé, Stephanie and Martín Uribe, "Optimal Fiscal and Monetary Policy under Imperfect Competition," Journal of Macroeconomics 26, June 2004(b), 183-209.

Schmitt-Grohé, Stephanie and Martín Uribe, "Optimal Operational Monetary Policy in the Christiano-Eichenbaum-Evans Model of the U.S. Business Cycle," manuscript, Duke University, August 2004(c).

Schmitt-Grohé, Stephanie and Martín Uribe, "Solving Dynamic General Equilibrium Models Using a Second-Order Approximation to the Policy Function," Journal of Economic Dynamics and Control 28, January 2004d, 755-775.

Schmitt-Grohé, Stephanie and Martín Uribe, "Optimal Simple And Implementable Monetary and Fiscal Rules," manuscript, Duke University, May 2004e.

Schmitt-Grohé, Stephanie and Martín Uribe, "Government Transfers and the Friedman Rule," manuscript, Duke University, January 2005a.

Schmitt-Grohé, Stephanie and Martín Uribe, "Optimal Fiscal and Monetary Policy in a Medium-Scale Macroeconomic Model: Expanded Version," NBER Working Paper 11417, June 2005b.

Smets, Frank and Raf Wouters, "Shocks and Frictions in US Business Cycles: A Bayesian DSGE Approach," manuscript, European Central Bank, April 21, 2004.

Turnovsky, Stephen J. and Brock, William A. , "Time Consistency and Optimal Government Policies in Perfect Foresight Equilibrium," Journal of Public Economics, 13, April 1980, $183-212$.

Woodford, Michael D., Interest and Prices, Princeton University Press: Princeton, New Jersey, 2003

Yun, Tack, "Nominal price rigidity, money supply endogeneity, and business cycles," Journal of Monetary Economics 37, 1996, 345-370. 


\section{Footnotes}

${ }^{1}$ Examples of this line of research include Ireland (1997), Rotemberg and Woodford (1997), Woodford (2003), and Clarida, Galí, and Gertler (1999), among many others.

${ }^{2} \mathrm{~A}$ formal analytical derivation of the result that the Friedman rule fails in the presence of government transfers is given in Schmitt-Grohé and Uribe (2005a).

${ }^{3}$ The model presented in Judd can be alternatively interpreted as one where the depreciation rate is positive and the production function represents output net of depreciation. Under this interpretation, however, Judd's measure of the markup would not be directly comparable to ours.

${ }^{4}$ To see why the level of capacity utilization $u_{t}$ is less than one (which is necessary for $\left(a\left(u_{t}\right)\right)$ to be negative) in the Ramsey equilibrium, recall that in the competitive equilibrium used for the calibration of the function $a(\cdot)$, the tax rate on capital was set at 40.7 percent and $u_{t}$ was set at unity. In the Ramsey equilibrium, $\tau^{k}$ is negative, which induces a larger level of capital. With a higher capital stock, its rate of return at full utilization falls, which induces capitalists to lower it degree of utilization. In the steady state shown in line 5 of table2, $u$ equals 0.85 .

${ }^{5}$ More recently, Benigno and Woodford (2005) arrive at a similar conclusion in the context of optimal taxation in the standard RBC model. They show that the first- and second-order approximations of the Ramsey equilibrium conditions are similar to the approximation based on a minimum-weighted-residual method reported in Chari et al. (1995).

${ }^{6}$ To the best of our knowledge, Chari et al. (1991) represents the first quantitative demonstration that the Ramsey rate of inflation in a flexible-price economy is highly volatile and unforecastable. However, the idea that surprise inflation is a tax on the stock of outstanding nominal government liabilities and that as a result the Ramsey rate of inflation should have dynamic properties akin to the Ramsey capital-income tax rate has been articulated by Turnovsky and Brock (1980), Judd (1992), and Calvo and Guidotti (1990,1993). 
${ }^{7}$ The result that inflation volatility rises significantly when product prices are allowed to be flexible but wages are sticky is sensitive to the battery of shocks driving business cycles. Chugh (2005) shows that when the sole source of uncertainty is innovations in government spending, then the Ramsey outcome implies low inflation volatility when prices are flexible but wages are sticky. Indeed, in our model, when prices are flexible but wages are sticky, the volatility of inflation is 5.8 percent in the environment with productivity and government spending shocks but only 0.3 percent in an environment with only government purchases shocks. The intuition for why adding productivity shocks increases the optimal volatility of inflation when prices are flexible and wages are sticky, stems from the fact that in response to productivity shocks, the real wage tends to move more than in response to government spending shocks and that the role of inflation is to bring real wages closer to their efficient level. It follows that the high volatility of inflation in the case of sticky wages and flexible prices is not fiscal in nature.

${ }^{8}$ One exception is the fact that the mean rate of inflation increases dramatically when product prices are flexible. As discussed earlier in section 3.1, the reason why the Ramsey planner chooses to inflate when all prices are flexible, is that inflation is an indirect tax on transfer payments.

${ }^{9}$ Under this higher level of wage stickiness and price flexibility (i.e., $\tilde{\alpha}=0.87$ and $\alpha=0$ ), the optimal inflation volatility is 7.8 percent. On the other hand, under sticky prices and flexible wages (i.e., $\tilde{\alpha}=0$ and $\alpha=0.6$ ), the optimal inflation volatility is 0.2 percent. Hence, when price stickiness takes its baseline value but wage stickiness is higher than in the baseline case (i.e., $\tilde{\alpha}=0.87$ and $\alpha=0.6$ ), the inflation volatility is closer to the figure associated with product-price rigidity alone.

${ }^{10}$ Formally, the wage-inflation Phillips curve can be written up to first order as $\hat{\pi}_{t}^{W}=$ 
${ }^{10}$ Formally, the wage-inflation Phillips curve can be written up to first order as $\hat{\pi}_{t}^{W}=$ $\beta E_{t} \hat{\pi}_{t+1}^{W}-\kappa \hat{\tilde{\mu}}_{t}$, where $\pi_{t}^{W} \equiv W_{t} / W_{t-1}$ denotes wage inflation and $\tilde{\mu}_{t}$ denotes the wage markup. The difference between our approach to modeling the labor market and the one adopted in Erceg et al. (2000) is the size of the parameter $\kappa$. Under our specification, we have that $\kappa=$ $\kappa^{S G U} \equiv(1-\tilde{\alpha})(1-\tilde{\alpha} \beta) / \tilde{\alpha}$. The Erceg et al. specification implies that $\kappa=\kappa^{S G U} /(1+E H L)$, where $E H L$ is a positive constant.

${ }^{11} \mathrm{~A}$ further criterion one could impose is that the nominal interest rate not violate the zero bound. In Schmitt-Grohé and Uribe (2004c), we approximate this constraint by requiring that in the competitive equilibrium the standard deviation be less than a fraction of the steady-state value of the nominal interest rate.

${ }^{12} \mathrm{~A}$ formal derivation of this welfare cost measure is presented in the expanded version of this paper (Schmitt-Grohé and Uribe, 2005b).

${ }^{13}$ Our computational strategy does not allow us to consider the case that tax rates are bounded above and below explicitly. But even if one were to use an alternative computational method, one should find that Ramsey capital income tax rates vary significantly over the business cycle.

${ }^{14}$ Chari et. al. consider an annual calibration (that is somewhat different from the one considered here) with business cycles driven by government purchases and technology shocks. Recently, Benigno and Woodford (2005) using a different numerical technique replicate this finding. As a test of our numerical procedure, we also study this economy and are able to reproduce the numbers reported in Benigno and Woodford. 
Table 1: Structural Parameters

\begin{tabular}{|c|c|c|}
\hline Parameter & Value & Description \\
\hline$\beta$ & 0.9902 & Subjective discount factor (quarterly) \\
\hline$\theta$ & 0.25 & Share of capital in value added \\
\hline$\psi$ & 0.0594 & Fixed cost \\
\hline$\delta$ & 0.0173 & Depreciation rate (quarterly) \\
\hline$\nu$ & 0.5114 & Fraction of wage bill subject to a CIA constraint \\
\hline$\eta$ & 6 & Price-elasticity of demand for a specific good variety \\
\hline$\tilde{\eta}$ & 21 & Wage-elasticity of demand for a specific labor variety \\
\hline$\alpha$ & 0.6 & Fraction of firms not setting prices optimally each quarter \\
\hline$\tilde{\alpha}$ & 0.64 & Fraction of labor markets not setting wages optimally each quarter \\
\hline$b$ & 0.65 & Degree of habit persistence \\
\hline$\phi_{1}$ & 0.0267 & Transaction cost parameter \\
\hline$\phi_{2}$ & 0.1284 & Transaction cost parameter \\
\hline$\phi_{3}$ & 1 & Preference parameter \\
\hline$\phi_{4}$ & 0.75 & Preference parameter \\
\hline$\kappa$ & 2.48 & Parameter governing investment adjustment costs \\
\hline$\gamma 1$ & 0.0339 & Parameter of capacity-utilization cost function \\
\hline$\gamma 2$ & 0.0685 & Parameter of capacity-utilization cost function \\
\hline$\chi$ & 0 & Degree of price indexation \\
\hline$\tilde{\chi}$ & 1 & Degree of wage indexation \\
\hline $\bar{g}$ & 0.0505 & Steady-state value of government consumption (quarterly) \\
\hline $\bar{n}$ & 0.0232 & Steady-state value of government transfers (quarterly) \\
\hline$\rho_{z}$ & 0.8556 & Serial correlation of the log of the technology shock \\
\hline$\sigma_{\epsilon^{z}}$ & 0.0064 & Std. dev. of the innovation to log of technology \\
\hline$\rho_{g}$ & 0.87 & Serial correlation of the log of government spending \\
\hline$\sigma_{\epsilon^{g}}$ & 0.016 & Std. dev. of the innovation to log of gov. consumption \\
\hline$\rho_{n}$ & 0.78 & Serial correlation of the log of government transfers \\
\hline$\sigma_{\epsilon^{n}}$ & 0.022 & Std. dev. of the innovation to log of gov. transfers \\
\hline$b / y$ & 1.68 & Debt-to-GDP ratio (quarterly) \\
\hline
\end{tabular}


Table 2: Ramsey Steady States

\begin{tabular}{cccc|ccccc}
\hline \hline \multicolumn{3}{c|}{ Environment } & \multicolumn{5}{c}{ Steady-State Outcome } \\
$\tau_{t}^{\phi}$ & $\chi$ & $\bar{n}$ & $\gamma_{2}$ & $\pi$ & $R$ & $\tau^{h}$ & $\tau^{k}$ & profit share \\
\hline$\tau_{t}^{k}$ & & & & 0.2 & 4.2 & 35.4 & -6.3 & 0.6 \\
$\tau_{t}^{k}$ & 1 & & & 4.6 & 8.8 & 34.7 & -6.6 & 0.6 \\
$\tau_{t}^{k}$ & 1 & 0 & & -3.8 & 0 & 24.1 & -5.3 & 2.3 \\
$\tau_{t}^{k}$ & & 0 & & -0.2 & 3.8 & 23.3 & -5.2 & 2.3 \\
1 & & & & 0.3 & 4.3 & 38.2 & -44.3 & 0.8 \\
1 & & & 6850 & 0.3 & 4.3 & 37.8 & -84.9 & 1.4 \\
$\tau_{t}^{k}, \tau_{t}^{h}$ & & & & & & & & \\
1 & & & & & & & \\
\hline
\end{tabular}

Note: The inflation rate, $\pi$, and the nominal interest rate, $R$, are expressed in percent per year. The labor income tax rate, $\tau^{h}$, and the capital income tax rate, $\tau^{k}$, are expressed in percent. Unless indicated otherwise, parameters take their baseline values, given in table 1 . 
Table 3: Cyclical Implications of Optimal Policy Under Income Taxation

\begin{tabular}{lcccc}
\hline \hline Variable & $\begin{array}{c}\text { Steady } \\
\text { state }\end{array}$ & $\begin{array}{r}\text { Standard } \\
\text { deviation }\end{array}$ & $\begin{array}{c}\text { Serial } \\
\text { correlation }\end{array}$ & $\begin{array}{c}\text { Correlation } \\
\text { with output }\end{array}$ \\
\hline$\tau_{t}^{y}$ & 30 & 1.1 & 0.62 & -0.51 \\
$R_{t}$ & 4.53 & 1.43 & 0.74 & -0.11 \\
$\pi_{t}$ & 0.51 & 1.1 & 0.55 & 0.11 \\
$y_{t}$ & 0.3 & 1.96 & 0.97 & 1 \\
$c_{t}$ & 0.21 & 1.16 & 0.98 & 0.89 \\
$i_{t}$ & 0.04 & 7.87 & 0.98 & 0.95 \\
$h_{t}$ & 0.19 & 1.34 & 0.75 & 0.59 \\
$w_{t}$ & 1.17 & 0.94 & 0.93 & 0.80 \\
$a_{t}$ & 0.72 & 4.44 & 0.99 & 0.31 \\
\hline \hline
\end{tabular}

Note: $R_{t}$ and $\pi_{t}$ are expressed in percent per year, and $\tau_{t}^{y}$ is expressed in percent. The steady-state values of $y_{t}, c_{t}, i_{t}, w_{t}$, and $a_{t}$ are expressed in levels. The standard deviations, serial correlations, and correlations with output of these 5 variables correspond to percent deviations from their steady-state values. 
Table 4: Degree of Nominal Rigidity and Optimal Policy

\begin{tabular}{|c|c|c|c|c|c|c|c|}
\hline \multicolumn{8}{|c|}{ A. No Transfers $\left(n_{t}=0\right)$} \\
\hline$\alpha$ & $\tilde{\alpha}$ & & $\tau_{t}^{y}$ & $R_{t}$ & $\pi_{t}$ & $w_{t}$ & $a_{t}$ \\
\hline \multirow{3}{*}{0} & \multirow{3}{*}{0} & Mean & 19.0 & 4.4 & 0.4 & 1.2 & 0.8 \\
\hline & & Std. dev. & 0.1 & 0.2 & 5.8 & 1.4 & 2.5 \\
\hline & & Ser. corr. & 0.6 & 0.8 & -0.1 & 0.8 & 0.84 \\
\hline \multirow{3}{*}{0.6} & \multirow{3}{*}{0} & Mean & 19.0 & 4.0 & 0.02 & 1.2 & 0.8 \\
\hline & & Std. dev. & 0.4 & 0.7 & 0.1 & 1.4 & 6.3 \\
\hline & & Ser. corr. & 0.6 & 0.9 & 0.1 & 0.9 & 1 \\
\hline \multirow{3}{*}{0} & \multirow{3}{*}{0.64} & Mean & 19.0 & 4.4 & 0.4 & 1.2 & 0.8 \\
\hline & & Std. dev. & 1.5 & 3.1 & 5.8 & 1.7 & 5.1 \\
\hline & & Ser. corr & 0.5 & 0.9 & 0.8 & 0.8 & 0.99 \\
\hline \multirow{3}{*}{0.6} & \multirow{3}{*}{0.64} & Mean & 19.0 & 4.0 & 0.02 & 1.2 & 0.8 \\
\hline & & Std. dev. & 1.0 & 1.3 & 1.1 & 1 & 3.6 \\
\hline & & Ser. corr. & 0.6 & 0.7 & 0.6 & 0.9 & 0.99 \\
\hline \multicolumn{8}{|c|}{ B. Baseline Transfers } \\
\hline \multirow{3}{*}{0} & \multirow{3}{*}{0} & Mean & 27.5 & 21.2 & 16.6 & 1.2 & 0.7 \\
\hline & & Std. dev. & 0.5 & 0.5 & 6.8 & 1.5 & 3.0 \\
\hline & & Ser. corr. & 0.4 & 0.9 & -0.0 & 0.8 & 0.84 \\
\hline \multirow{3}{*}{0.6} & \multirow{3}{*}{0} & Mean & 30.0 & 4.5 & 0.5 & 1.2 & 0.7 \\
\hline & & Std. Dev. & 0.6 & 0.9 & 0.2 & 1.3 & 7.0 \\
\hline & & Ser. corr. & 0.7 & 0.6 & 0.1 & 0.7 & 1 \\
\hline \multirow{3}{*}{0} & \multirow{3}{*}{0.64} & Mean & 27.5 & 21.2 & 16.6 & 1.2 & 0.7 \\
\hline & & Std. dev. & 1.3 & 4.6 & 6.6 & 1.9 & 4.3 \\
\hline & & Ser. corr. & 0.5 & 0.9 & 0.83 & 0.8 & 0.99 \\
\hline \multirow{3}{*}{0.6} & \multirow{3}{*}{0.64} & Mean & 30 & 4.5 & 0.5 & 1.2 & 0.7 \\
\hline & & Std. dev. & 1.1 & 1.4 & 1.1 & 0.9 & 4.4 \\
\hline & & Ser. corr. & 0.6 & 0.7 & 0.6 & 0.9 & 0.99 \\
\hline \multirow{3}{*}{0.6} & \multirow{3}{*}{0.87} & Mean & 30 & 4.5 & 0.5 & 1.2 & 0.7 \\
\hline & & Std. dev. & 2.0 & 1.4 & 1.8 & 0.9 & 3.7 \\
\hline & & Ser. corr. & 0.5 & 0.6 & 0.7 & 0.9 & 0.99 \\
\hline
\end{tabular}

Note: See note to table 3. 
Table 5: Indexation and Optimal Policy

\begin{tabular}{|c|c|c|c|c|c|c|c|}
\hline$\chi$ & $\tilde{\chi}$ & & $\tau_{t}^{y}$ & $R_{t}$ & $\pi_{t}$ & $w_{t}$ & $a_{t}$ \\
\hline \multirow{3}{*}{0} & \multirow{3}{*}{0} & Mean & 30 & 4.1 & 0.11 & 1.2 & 0.72 \\
\hline & & Std. dev. & 0.66 & 1.2 & 0.94 & 1 & 4.9 \\
\hline & & Ser. corr. & 0.56 & 0.6 & 0.44 & 0.96 & 0.99 \\
\hline \multirow{3}{*}{1} & \multirow{3}{*}{0} & Mean & 30 & 4.1 & 0.13 & 1.2 & 0.72 \\
\hline & & Std. dev. & 0.66 & 1 & 1.1 & 1.1 & 5 \\
\hline & & Ser. corr. & 0.51 & 0.58 & 0.77 & 0.96 & 0.99 \\
\hline \multirow{3}{*}{0} & \multirow{3}{*}{1} & Mean & 30 & 4.5 & 0.51 & 1.2 & 0.72 \\
\hline & & Std. dev. & 1.1 & 1.4 & 1.1 & 0.95 & 4.3 \\
\hline & & Ser. corr. & 0.62 & 0.74 & 0.55 & 0.93 & 0.99 \\
\hline \multirow{3}{*}{1} & \multirow{3}{*}{1} & Mean & 28 & 21 & 17 & 1.1 & 0.74 \\
\hline & & Std. dev. & 1 & 2.7 & 2.9 & 1.2 & 4 \\
\hline & & Ser. corr. & 0.47 & 0.88 & 0.94 & 0.96 & 1 \\
\hline
\end{tabular}

Note: See note to table 3. 
Table 6: Optimal Policy With One Policy Instrument

\begin{tabular}{|c|c|c|c|c|c|c|}
\hline \multirow[b]{2}{*}{ Variable } & \multicolumn{3}{|c|}{ Standard Deviation } & \multicolumn{3}{|c|}{ Serial Correlation } \\
\hline & $\begin{array}{l}\text { Optimal } \\
\text { Monetary \& Fiscal } \\
\text { Policy }\end{array}$ & $\begin{array}{l}\text { Optimal } \\
\text { Fiscal } \\
\text { Policy }\end{array}$ & $\begin{array}{l}\text { Optimal } \\
\text { Monetary } \\
\text { Policy }\end{array}$ & $\begin{array}{c}\text { Optimal } \\
\text { Monetary \& Fiscal } \\
\text { Policy }\end{array}$ & $\begin{array}{l}\text { Optimal } \\
\text { Fiscal } \\
\text { Policy }\end{array}$ & $\begin{array}{l}\text { Optimal } \\
\text { Monetary } \\
\text { Policy }\end{array}$ \\
\hline$\tau_{t}^{y}$ & 1.09 & 0.71 & 1.74 & 0.62 & 0.93 & 0.85 \\
\hline$R_{t}$ & 1.43 & 2.25 & 1.4 & 0.74 & 0.53 & 0.53 \\
\hline$\pi_{t}$ & 1.1 & 1.5 & 1.33 & 0.55 & 0.53 & 0.55 \\
\hline$y_{t}$ & 1.98 & 1.74 & 2.5 & 0.97 & 0.97 & 0.98 \\
\hline$c_{t}$ & 1.17 & 1.1 & 1.52 & 0.98 & 0.97 & 0.99 \\
\hline$i_{t}$ & 8.01 & 6.88 & 10.6 & 0.98 & 0.99 & 0.99 \\
\hline$h_{t}$ & 1.34 & 1.13 & 1.96 & 0.75 & 0.80 & 0.87 \\
\hline$w_{t}$ & 0.96 & 1.07 & 0.99 & 0.94 & 0.9 & 0.9 \\
\hline$a_{t}$ & 4.43 & 6.28 & 0 & 0.99 & 1 & 0 \\
\hline Welfare Cost & $\$ 0.00$ & $\$ 9.10$ & $\$ 2.30$ & & & \\
\hline
\end{tabular}

Note: In the case of optimal fiscal policy only, monetary policy takes the form of a Taylor rule, $R_{t} / R=\left(\pi_{t} / \pi\right)^{1.5}$ (in this formula, we use the notation used in the exposition of the paper, so that $R_{t}$ and $\pi_{t}$ are expressed in gross quarterly rates), where $R$ and $\pi$ denote, respectively, the steady-state values of $R_{t}$ and $\pi_{t}$ in the Ramsey equilibrium with optimal fiscal and monetary policy. In the case of optimal monetary policy only, fiscal policy consists in keeping real government liabilities constant, that is, $a_{t}=a$, where $a$ denotes the steady-state value of $a_{t}$ in the Ramsey equilibrium with optimal fiscal and monetary policy. The variables $R_{t}$ and $\pi_{t}$ are expressed in percent per year, and $\tau_{t}^{y}$ is expressed in percent. The standard deviations and serial correlations of output, consumption, investment, hours, wages, and government liabilities correspond to percent deviations from their steady-state values. The welfare cost is measured in dollars of 2003 per person per year and is defined as the compensation needed to make the representative agent indifferent between living in a world with the policy indicated in the respective column heading and living in a world where both monetary and fiscal policy are Ramsey optimal. 
Figure 1: Impulse Response To A Productivity Shock
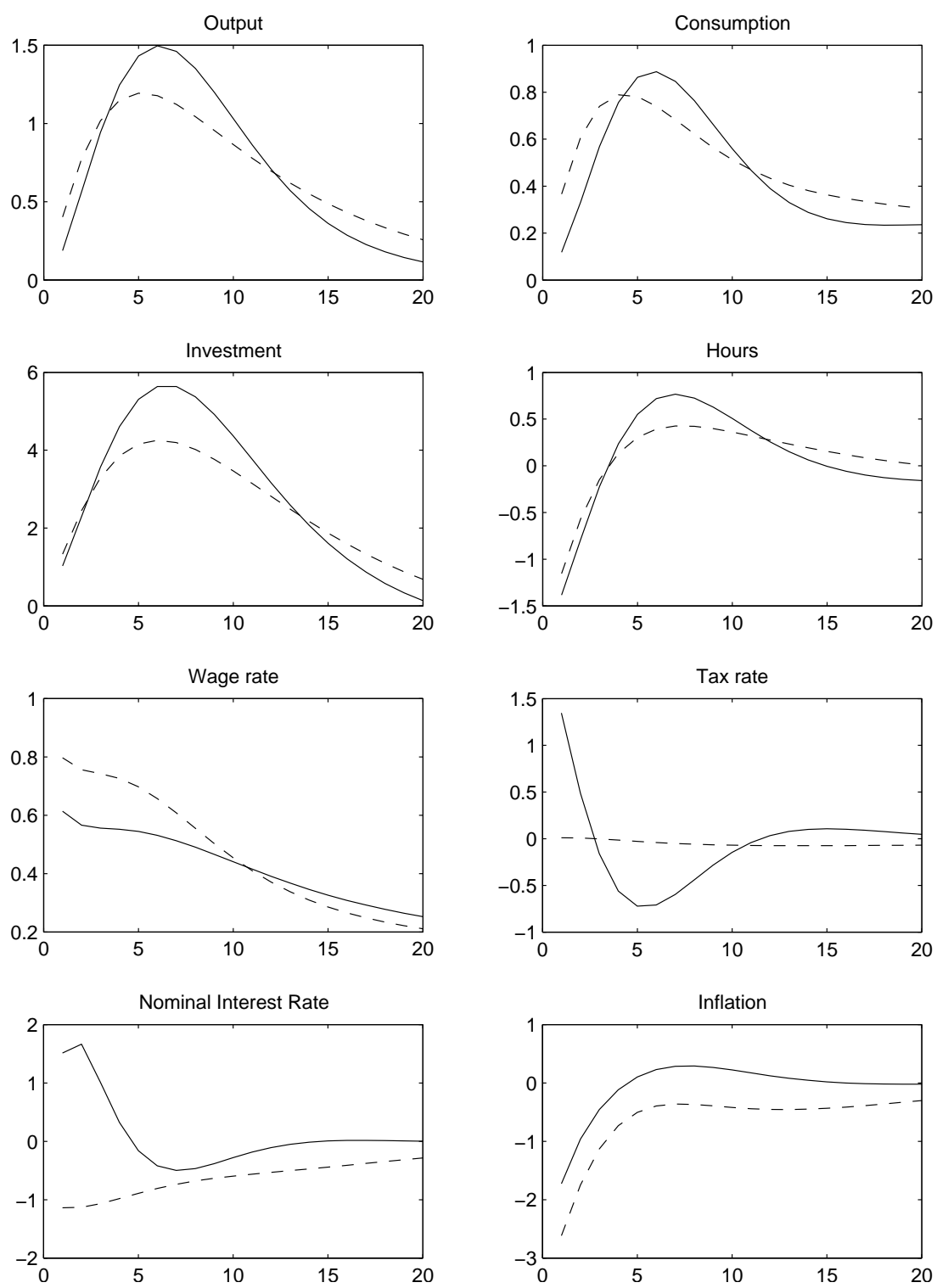

Ramsey Policy

- . - Optimized Rule

Note: The size of the initial innovation to the technology shock is one standard deviation, $\ln \left(z_{1}\right)=1.2 \%$. The nominal interest rate and the inflation rate are expressed in percent per year, the tax rate is expressed in percentage points, and the remaining variables are expressed in percentage deviations from their respective steady-state values. 
Figure 2: Impulse Response To A Government Spending Shock
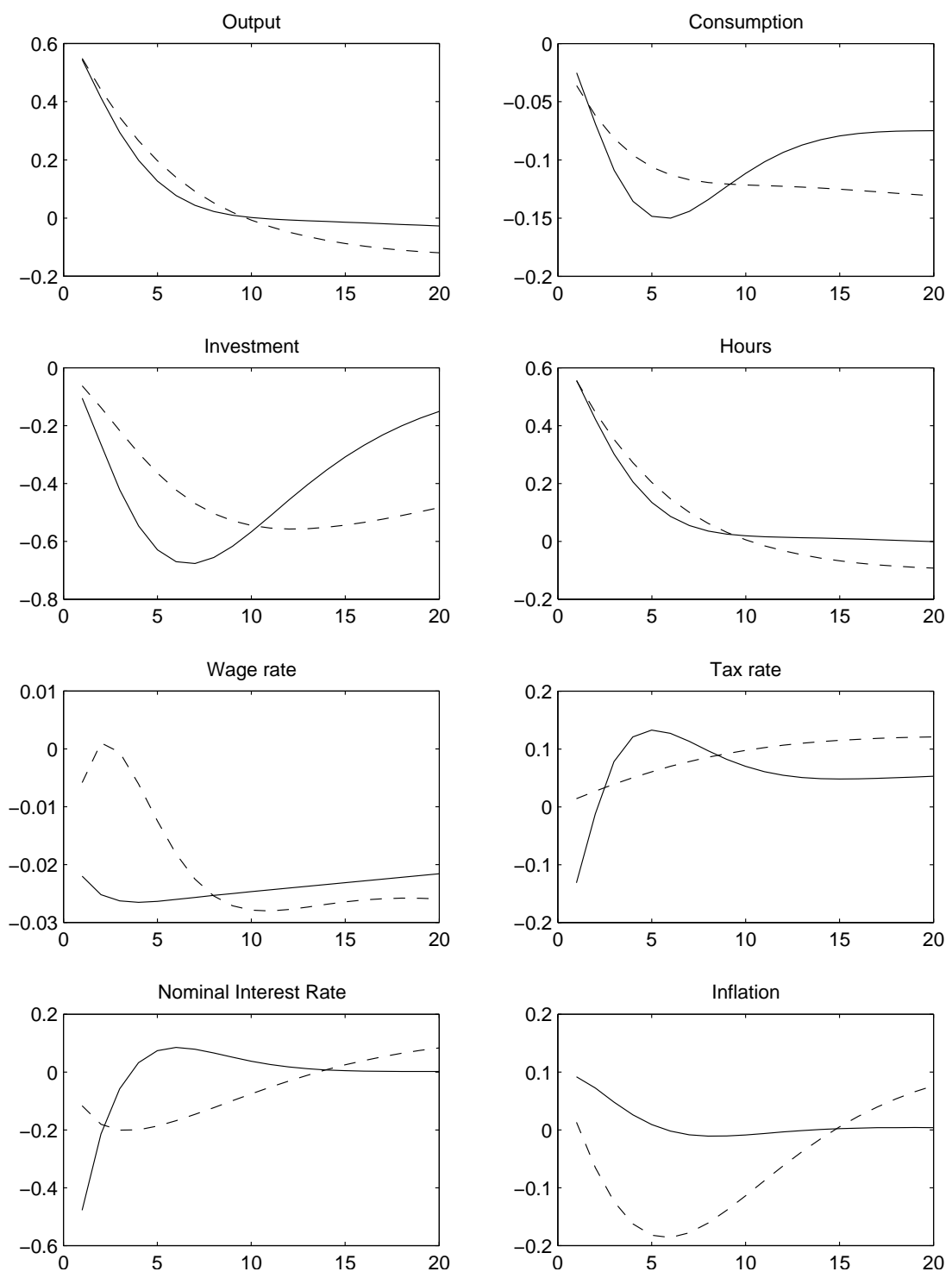

Ramsey Policy

- _ _ Optimized Rule

Note: The size of the initial innovation to the government spending shock is one standard deviation, $\ln \left(g_{1} / \bar{g}\right)=3.2 \%$. The nominal interest rate and the inflation rate are expressed in percent per year, the tax rate is expressed in percentage points, and the remaining variables are expressed in percentage deviations from their respective steady-state values. 
Figure 3: Impulse Response To A Government Transfer Shock
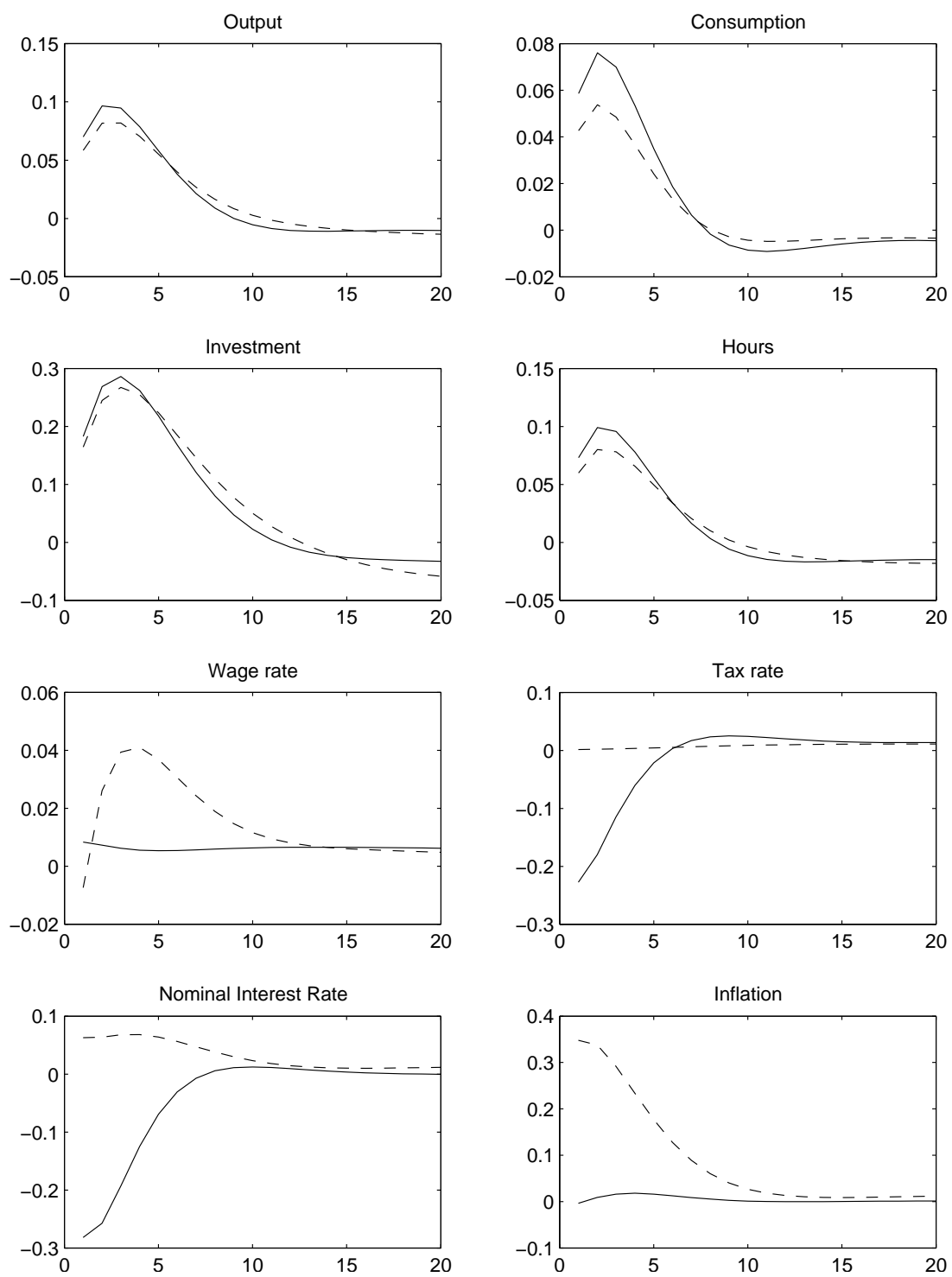

Ramsey Policy

- . . - Optimized Rule

Note: The size of the initial innovation to the government spending shock is one standard deviation, $\ln \left(n_{1} / \bar{n}\right)=3.5 \%$. The nominal interest rate and the inflation rate are expressed in percent per year, the tax rate is expressed in percentage points, and the remaining variables are expressed in percentage deviations from their respective steady-state values. 
Figure 4: Time to Tax and Capital Tax Rate Volatility

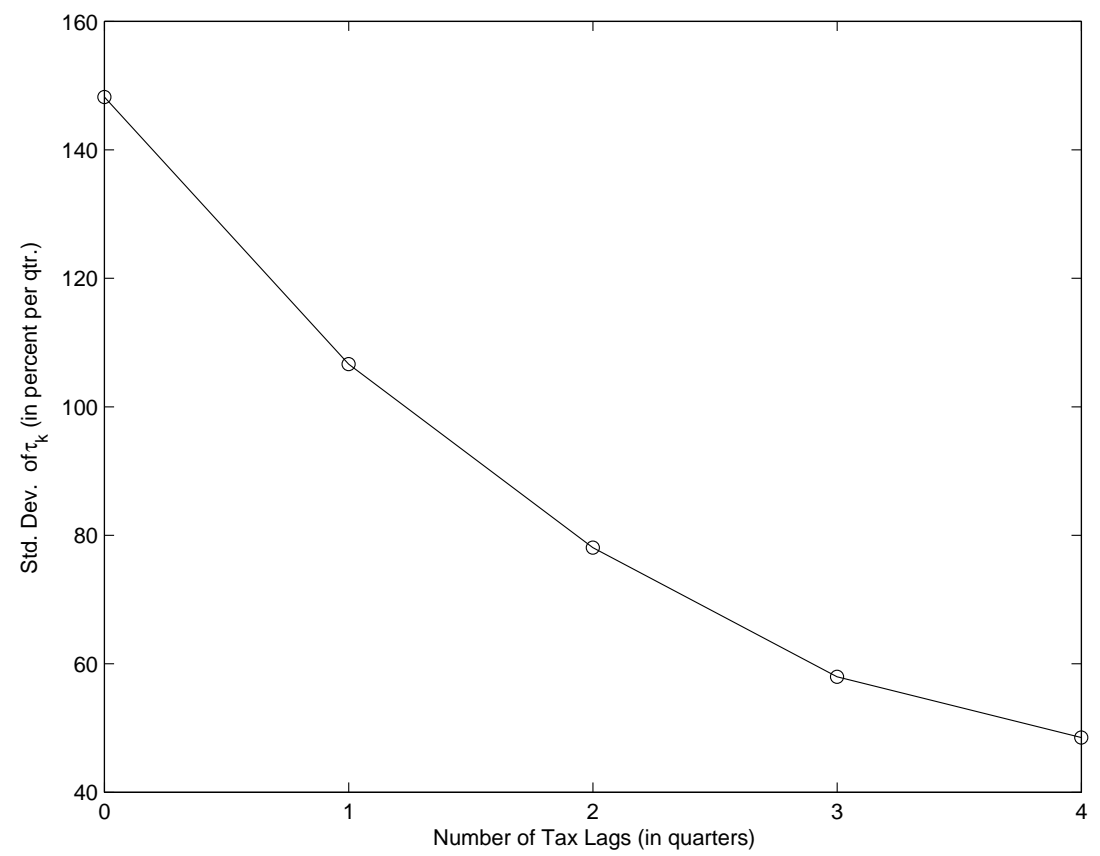

Note: The standard deviation of the capital income tax rate is expressed in percentage points. 


\section{European Central Bank Working Paper Series}

For a complete list of Working Papers published by the ECB, please visit the ECB's website (http://www.ecb.int)

570 "Household debt sustainability: what explains household non-performing loans? An empirical analysis" by L. Rinaldi and A. Sanchis-Arellano, January 2006.

57I “Are emerging market currency crises predictable? A test” by T. A. Peltonen, January 2006.

572 "Information, habits, and consumption behavior: evidence from micro data" by M. Kuismanen and L. Pistaferri, January 2006.

573 "Credit chains and the propagation of financial distress" by F. Boissay, January 2006.

574 "Inflation convergence and divergence within the European Monetary Union" by F. Busetti, L. Forni, A. Harvey and F. Venditti, January 2006.

575 "Growth in euro area labour quality" by G. Schwerdt and J. Turunen, January 2006.

576 “Debt stabilizing fiscal rules” by P. Michel, L. von Thadden and J.-P. Vidal, January 2006.

577 “Distortionary taxation, debt, and the price level” by A. Schabert and L. von Thadden, January 2006.

578 "Forecasting ECB monetary policy: accuracy is (still) a matter of geography" by H. Berger, M. Ehrmann and M. Fratzscher, January 2006.

579 "A disaggregated framework for the analysis of structural developments in public finances" by J. Kremer, C. Rodrigues Braz, T. Brosens, G. Langenus, S. Momigliano and M. Spolander, January 2006.

580 "Bank interest rate pass-through in the euro area: a cross country comparison" by C. K. Sørensen and T. Werner, January 2006.

$58 \mathrm{I}$ "Public sector efficiency for new EU Member States and emerging markets" by A. Afonso, L. Schuknecht and V. Tanzi, January 2006.

582 "What accounts for the changes in U.S. fiscal policy transmission?" by F. O. Bilbiie, A. Meier and G. J. Müller, January 2006.

583 "Back to square one: identification issues in DSGE models" by F. Canova and L. Sala, January 2006.

584 “A new theory of forecasting” by S. Manganelli, January 2006.

585 "Are specific skills an obstacle to labor market adjustment? Theory and an application to the EU enlargement” by A. Lamo, J. Messina and E. Wasmer, February 2006.

586 "A method to generate structural impulse-responses for measuring the effects of shocks in structural macro models" by A. Beyer and R. E. A. Farmer, February 2006. 
587 "Determinants of business cycle synchronisation across euro area countries" by U. Böwer and C. Guillemineau, February 2006.

588 "Rational inattention, inflation developments and perceptions after the euro cash changeover" by M. Ehrmann, February 2006.

589 "Forecasting economic aggregates by disaggregates" by D. F. Hendry and K. Hubrich, February 2006.

590 "The pecking order of cross-border investment" by C. Daude and M. Fratzscher, February 2006.

59 I "Cointegration in panel data with breaks and cross-section dependence" by A. Banerjee and J. L. Carrion-i-Silvestre, February 2006.

592 "Non-linear dynamics in the euro area demand for MI" by A. Calza and A. Zaghini, February 2006.

593 “Robustifying learnability” by R. J. Tetlow and P. von zur Muehlen, February 2006.

594 “The euro's trade effects" by R. Baldwin, comments by J. A. Frankel and J. Melitz, March 2006.

595 "Trends and cycles in the euro area: how much heterogeneity and should we worry about it?" by D. Giannone and L. Reichlin, comments by B. E. Sørensen and M. McCarthy, March 2006.

596 "The effects of EMU on structural reforms in labour and product markets" by R. Duval and J. Elmeskov, comments by S. Nickell and J. F. Jimeno, March 2006.

597 "Price setting and inflation persistence: did EMU matter?" by I. Angeloni, L. Aucremanne, M. Ciccarelli, comments by W. T. Dickens and T. Yates, March 2006.

598 "The impact of the euro on financial markets" by L. Cappiello, P. Hördahl, A. Kadareja and S. Manganelli, comments by X. Vives and B. Gerard, March 2006.

599 "What effects is EMU having on the euro area and its Member Countries? An overview" by F. P. Mongelli and J. L. Vega, March 2006.

600 "A speed limit monetary policy rule for the euro area” by L. Stracca, April 2006.

60I "Excess burden and the cost of inefficiency in public services provision" by A. Afonso and V. Gaspar, April 2006.

602 "Job flow dynamics and firing restrictions: evidence from Europe" by J. Messina and G. Vallanti, April 2006.

603 “Estimating multi-country VAR models" by F. Canova and M. Ciccarelli, April 2006.

604 “A dynamic model of settlement" by T. Koeppl, C. Monnet and T. Temzelides, April 2006.

605 “(Un)Predictability and macroeconomic stability” by A. D’Agostino, D. Giannone and P. Surico, April 2006.

606 "Measuring the importance of the uniform nonsynchronization hypothesis" by D. A. Dias, C. Robalo Marques and J. M. C. Santos Silva, April 2006. 
607 "Price setting behaviour in the Netherlands: results of a survey" by M. Hoeberichts and A. Stokman, April 2006.

608 "How does information affect the comovement between interest rates and exchange rates?" by M. Sánchez, April 2006.

609 "The elusive welfare economics of price stability as a monetary policy objective: why New Keynesian central bankers should validate core inflation” by W. H. Buiter, April 2006.

610 "Real-time model uncertainty in the United States: the Fed from 1996-2003" by R. J. Tetlow and B. Ironside, April 2006.

6II "Monetary policy, determinacy, and learnability in the open economy" by J. Bullard and E. Schaling, April 2006.

612 "Optimal fiscal and monetary policy in a medium-scale macroeconomic model" by S. Schmitt-Grohé and M. Uribe, April 2006. 
